\title{
A New Insight of Salt Stress Signaling in Plant
}

\author{
Hee Jin Park', Woe-Yeon Kim ${ }^{1,2}$, and Dae-Jin Yun ${ }^{1, *}$
}

\begin{abstract}
Many studies have been conducted to understand plant stress responses to salinity because irrigation-dependent salt accumulation compromises crop productivity and also to understand the mechanism through which some plants thrive under saline conditions. As mechanistic understanding has increased during the last decades, discovery-oriented approaches have begun to identify genetic determinants of salt tolerance. In addition to osmolytes, osmoprotectants, radical detoxification, ion transport systems, and changes in hormone levels and hormoneguided communications, the Salt Overly Sensitive (SOS) pathway has emerged to be a major defense mechanism. However, the mechanism by which the components of the sOS pathway are integrated to ultimately orchestrate plant-wide tolerance to salinity stress remains unclear. $A$ higher-level control mechanism has recently emerged as a result of recognizing the involvement of GIGANTEA (GI), a protein involved in maintaining the plant circadian clock and control switch in flowering. The loss of GI function confers high tolerance to salt stress via its interaction with the components of the SOS pathway. The mechanism underlying this observation indicates the association between GI and the SOS pathway and thus, given the key influence of the circadian clock and the pathway on photoperiodic flowering, the association between GI and SOS can regulate growth and stress tolerance. In this review, we will analyze the components of the SOS pathways, with emphasis on the integration of components recognized as hallmarks of a halophytic lifestyle.
\end{abstract}

\section{INTRODUCTION}

For maintaining photosynthesis and growth in plants, water supply is essential in natural settings and cropping systems to produce high yields. In agriculture, water supply is increasingly dependent on irrigation systems that currently cover approxi-

${ }^{1}$ Division of Applied Life Science (BK21 Plus Program), Plant Molecular Biology and Biotechnology Research Center, ${ }^{2}$ Institute of Agriculture \& Life Sciences, Graduate School of Gyeongsang National University, Jinju 52828, Korea

${ }^{*}$ Correspondence: djyun@gnu.ac.kr

Received 4 April, 2016; revised 6 May, 2016; accepted 16 May, 2016; published online 30 May, 2016

Keywords: circadian clock, GIGANTEA, NaCl, salinity, salt overly sensitive pathway mately $15 \%$ of agriculturally useful land, which produces more than a third of all food (Ghassemi et al., 1995; see also: USDA Salinity Laboratory, http://www.ars.usda.gov/Aboutus/docs.htm? docid=10201). The accumulation of sodium ions, although low in irrigation water, in soils is unavoidable unless leaching of salts into groundwater is economically possible.

$\mathrm{Na}^{+}$tolerance widely differs in plant species; for example, citrus, tomato, and avocado have a low tolerance, while cotton and barley have a high tolerance (Flowers et al., 2010). Most crops are glycophytes, indicating a requirement for fresh water, and their growth may be severely inhibited by often low (millimolar) $\mathrm{Na}^{+}$concentrations. Most crops are destroyed or will not produce fruits or set seeds in $100 \mathrm{mM} \mathrm{NaCl}$, i.e., approximately one fourth of the $\mathrm{NaCl}$ concentration of seawater (Flowers, 2004; Maas and Hoffman, 1977; Zhu, 2001).

Some plants, termed halophytes, naturally grow in or even depend on elevated or high $\mathrm{NaCl}$ environments (200 mM NaCl) (Bohnert and Cushman, 2000; Bohnert et al., 1995; Flowers and Colmer, 2008; Flowers et al., 1977; 2010). Numerous plant orders include many halophytic species, such as Atriplex, Salicornia, Mesembryanthemum, Rhizophora, and Suaeda, that can grow in an environment having up to $1000 \mathrm{mM} \mathrm{NaCl}$ (Black, 1960; Ushakova et al., 2005; Yeo and Flowers, 1980). Halophytes are found in all flowering plant taxa, although in different abundances, but constitute only approximately $5-10 \%$ of all known angiosperms (Yensen, 2006).

Salt stress negatively affects most plant growth phases and alters development (Munns, 2002; Sairam and Tyagi, 2004). Ion imbalances are particularly detrimental during germination and seedling growth; less so during the vegetative growth, more so when flowering is initiated, and again less as seeds are set. Salt shock is often used in experiments, although in nature, the ion concentrations typically gradually change. Within minutes following salt shock, water deficit and wilting occur because of rapid change in the osmotic potential difference between the plant and exterior environment (Fricke et al., 2006; Munns, 2002). Accompanying this water deficit stress are ABA biosynthesis and transportation throughout the plant initiating stomatal closure, among many other responses. The consequences, which are also contributed by ABA-independent mechanisms, are reduced transpiration and photosynthesis and increased photoinhibition and oxidative stress. Such stresses may be countered by the scavenging defenses of reactive oxygen species (ROS) that are induced by hormonal changes. Ultimately, a decreased in leaf and root growth rates will occur that may accelerate over time. Water deficit, hyperosmotic stress, nutritional imbalance, and hyperionic toxicity are physiological hallmarks that may eventually lead to death (Cheong and Yun, 2007; Cramer and Jones, 1996; Sairam and Tyagi, 
2004).

All plants express proteins for the uptake of ions into cells, excretion from cells, distribution across organs and cells, and storage in vacuoles that may often be confined to dedicated cells or older tissues that then senesce. Responding to ion imbalance changes in gene expression and metabolism can adjust to some degree that is species- and condition-specific respond to ionic challenges and osmotically to a new equilibrium (Fig. 1). As $\mathrm{NaCl}$ is partitioned in the vacuoles of elongating cells (Munns, 2005; Nawaz et al., 2010), signs of injury may appear first in older leaves within days or weeks. Subsequently, younger leaves are damaged, reducing photosynthetic performance, followed by delayed flowering and eventually affecting seed maturation in sensitive plants (Munns, 2002). However, altered development and flowering cannot be simply understood as a result of damaging salt concentrations that accumulate in plants. The susceptibility of plants to salinity stress is because of changes in molecular programs that affect development (Krasensky and Jonak, 2012).

In Arabidopsis, as observed earlier in rice, $\mathrm{NaCl}$ stress delays flowering (Li et al., 2007; Lutts et al., 1995); however, this behavior is not exhibited by all species, strongly suggesting that delayed flowering is genetically controlled (Andres and Coupland, 2012). However, the Arabidopsis relatives Thellungiella salsuginea and Schrenkiella parvula (formerly T. parvula) do flower faster, better, and earlier (Oh et al., 2014). Among other plants, the euhalophyte Mesembryanthemum crystallinum also employs this strategy (Adams et al., 1998).

Correlative evidence is also provided by other observations. For one, flowering time is an important trait in breeding crops (Jung and Müller, 2009). Second, flowering time loci have been associated with quantitative trait loci (QTLs) for tolerance to abiotic stress such as drought or cold (Ducrocq et al., 2008; Sehgal et al., 2012). Here we will examine recent findings regarding the manner in which defense mechanisms against salt stress and decisions regarding flowering in a saline environment are genetically regulated. A biochemical association exbetween the SOS salt exclusion pathway and proteins that regulate the entry into flowering (Kim et al., 2013; Park et al., 2013). Furthermore, we will discuss the emerging understanding regarding how changes in the plant growth phases can fundamentally alter the manner in which plants engage mechanisms that lead to stress tolerance or avoidance. Available data are insufficient to assert that the transition from the glycophytic to halophytic lifestyle may be relatively easy. However, hypothetically, plant-phase changes coincide with the initiation of new developmental programs that can or could evolve to adjust to prevailing environmental conditions. Thus, we will discuss how the circadian clock, day length, and progression from vegetative to reproductive growth altogether influence plant stress responses and how the imposition of salt stress can modulate phase changes and alter further growth (Bendix et al., 2013).

\section{SALINITY STRESS RESPONSES}

As outlined in Fig. 1, numerous concepts, mechanisms, and factors have emerged that have led to some understanding of the defenses available in plants to cope with and survive salt stress conditions. Further details have been outlined in several reviews (Bohnert and Jensen, 1996; Craig Plett and Møller, 2010; Howell, 2013; Kronzucker and Britto, 2011; Munns and Tester, 2008; Nuccio et al., 1999; Pardo, 2010). We provide a short synopsis of the salient concepts.

Salt stress is typically experimentally induced by elevated or increasing $\mathrm{NaCl}$ levels in the soil or medium. When a high salt concentration is rapidly applied, $\mathrm{NaCl}$ shock leads to a rapid osmotic challenge and water loss, followed more slowly by increased uptake of $\mathrm{Na}^{+}$and $\mathrm{Cl}^{-}$. When salt is gradually applied as may be the case in nature, the osmotic stress component is less pronounced and $\mathrm{Na}^{+}$concentration increases more slowly. However, the mechanisms that have been recognized, analyzed, and then verified in transgenic experiments have often employed (moderate) shock treatments (Shavrukov, 2013).

\section{Membrane integrity}

The most immediate event following salt-induced osmotic stress and water deficiency is the loss of turgor pressure, resulting from changes in cell structure and membrane leakage, and different compositions of cell membranes (Kinnunen, 2000; König et al., 2007). To maintain cell membrane integrity, membrane rearrangement processes occur in plant cells (Munnik and Vermeer, 2010). For example, the overexpression of phosphatidylinositol synthase genes in tobacco increases drought stress tolerance by modulating the membrane lipid composition (Liu et al., 2013a; Zhai et al., 2012).

\section{$\mathrm{Ca}^{2+}$ and IP3}

Osmotic stress imposed by $\mathrm{NaCl}$, drought, or cold transiently increases $\mathrm{Ca}^{2+}$ and inositol 1,4,5-trisphosphate (IP3) concentrations in the cytosol (DeWald et al., 2001). The biosynthesis of the IP3 precursor phosphoinositide phosphatidylinositol 4,5bisphosphate $\left[\mathrm{Ptdlns}(4,5) \mathrm{P}_{2}\right]$ is rapidly induced by $\mathrm{NaCl}$ treatment, and the increase in IP3 concentration appears to mediate cellular $\mathrm{Ca}^{2+}$ mobilization. Cytosolic calcium is translocated through $\mathrm{Ca}^{2+}$ pumps and channels that are present on the plasma membrane, tonoplast, and ER membrane. $\mathrm{Ca}^{2+}$ and IP3 fluxes act as secondary messengers in stress signal transduction (Sanders et al., 2002; Sairam and Tyagi, 2004; Zhu, 2001). The downstream activation of mitogen-activated protein kinase (MAPK) cascades regulates the gene expression by phosphorylating many transcriptional activators (Cheong and Yun, 2007; Nakagami et al., 2005; Sairam and Tyagi, 2004; Zhu, 2001; 2002).

\section{Osmolytes}

Osmotic imbalance and continued salt exposure inevitably leads to a water deficit, which is phenotypically shown by a partial loss of turgor. Plants activate mechanisms that lower the osmotic potential by generating osmotically active metabolites such as proline, sugars, and sugar alcohols (Bohnert et al., 1995). The type of accumulating osmolytes is to some degree species specific, and many of these compounds are also found in response to freezing, drought, and heat stresses. The soinclude sugars (sucrose and fructose), polyols (sorbitol, mannitol, glycerol, arabinitol, and pinitol), complex sugars (fructans, trehalose, and raffinose), ions (predominantly $\mathrm{K}^{+}$), specific proteins, and charged metabolites (betaine, proline, glutamate, aspartate, glycine, choline, putrescine, oxalate, and malate) (Cheong and Yun, 2007; Sairam and Tyagi, 2004). All osmolytes share a common characteristic, i.e., lowering the osmotic potential in the cytosolic compartment while not inhibiting metabolic reactions at relatively high concentrations. Osmolytes may also function as osmoprotectants of proteins, macromolecular aggregates, and membranes; as antioxidants in redox balance; and as signaling molecules. Consequently, transgenic plants that overexpress osmolytes, such as glycine betaine, proline, sugar alcohols, and fructans, demonstrate tolerance to multiple abiotic stresses such as salinity, freezing and heat (for further 


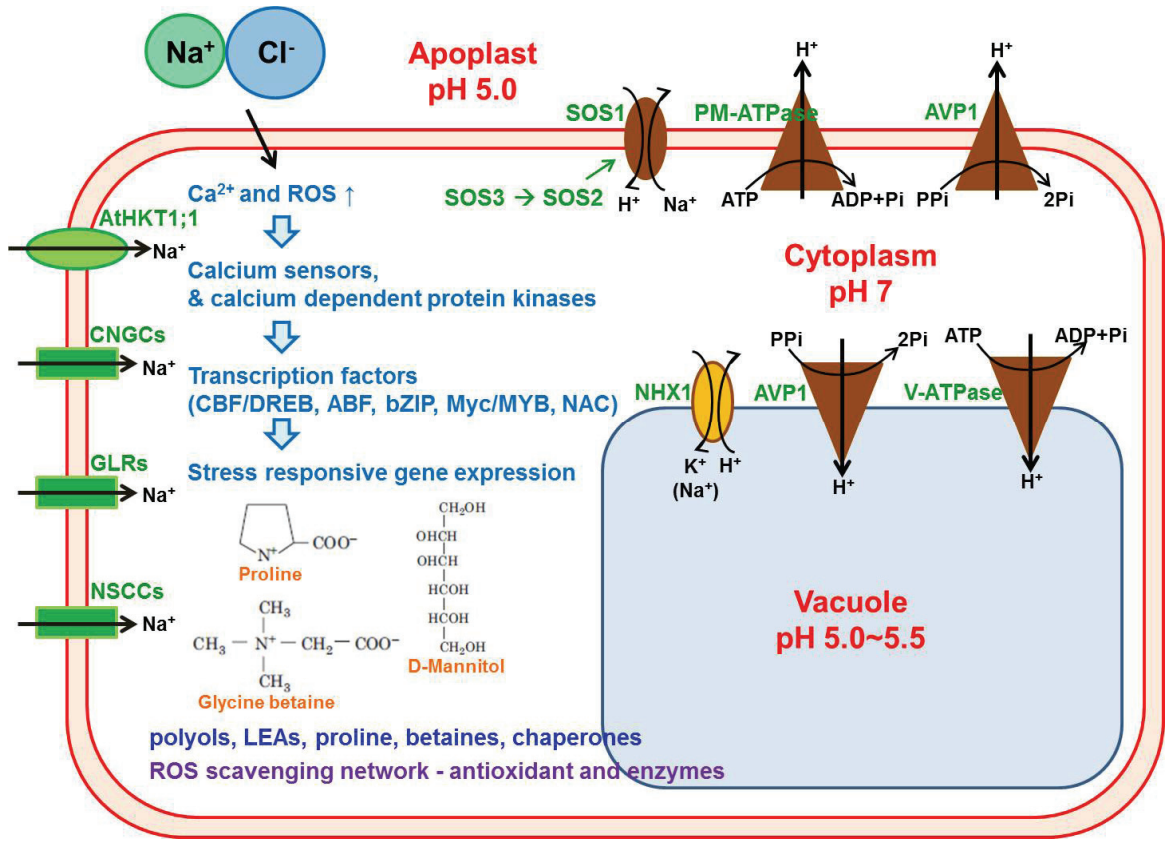

Fig. 1. A simplified model of plant cell sensing of stress, transduction of signals by transcriptional regulation, enzyme activity control, and translocational control. CYCLIC NUCLEOTIDEGATED CHANNELS (CNGCS), GLUTAMATE RECEPTOR (GLR), NONSELECTIVE CATION CHANNEL (NSCC), and HIGH AFFINITY $\mathrm{K}^{+}$ TRANSPORTER (HKT) mediate $\mathrm{Na}^{+}$ influx. SOS1 (plasma membrane $\mathrm{Na}^{+} / \mathrm{H}^{+}$antiporter) is involved in the extrusion of $\mathrm{Na}^{+}$from the cytoplasm and AtNHX1 mediates $\mathrm{K}^{+} / \mathrm{H}^{+}$exchanges, involved in controlling the vacuolar osmotic potential and regulating cytosolic $\mathrm{Na}^{+}-\mathrm{K}^{+}$ratio through vacuolar compartmentalization of $\mathrm{K}^{+}$. details regarding the protective roles of osmolytes refer to Cheong and Yun, 2007; Nuccio et al., 1999; Rontein et al., 2002; Sairam and Tyagi, 2004; Sakamoto and Murata, 2002; Wahid et al., 2007; Zhu, 2001).

Water uptake and transportation also constitute important parameters for maintaining osmotic balance, which is associated with aquaporins. Aquaporins are present in the plasma and tonoplast membranes and transport water, small neutral solutes, and gases, such as carbon dioxide or ammonia, across other internal membranes (del Martínez-Ballesta et al., 2006; ShatilCohen et al., 2011; Tyerman et al., 1999; Zhou et al., 2012).

\section{Soluble sugars as signals}

Soluble sugars are metabolic resources and structural components and may serve as signaling molecules under stress. Sucrose and glucose play roles as substrates for cellular respiration and as osmolytes, respectively. Fructose appears to be involved in secondary metabolite synthesis. Fluctuations in soluble sugar concentrations under stress affect $\mathrm{CO}_{2}$ assimilation, carbon partitioning, enzyme activities, and related gene expressions (for details, see Rosa et al., 2009).

\section{ROS}

Another phenotypic indicator of stress is stomatal closure, which is initiated by water deficit. The stomatal closure generates over time a multifaceted feedback process by which leaf and plant temperature increases, $\mathrm{CO}_{2}$ deficit becomes acute, and photosynthesis decreases or ceases. Altogether these factors lead to increased ROS production that must be countered by mechanisms such as flavonoid generation, $\mathrm{H}_{2} \mathrm{O}_{2}$ detoxification, and/or OH-radical scavenging (Blokhina et al., 2003; Shao et al., 2008). The biochemical inventory of plants for proteins in these defense mechanisms is large and multifaceted, indicating the fundamental importance of ROS scavenging (Dietz, 2003; Kar, 2011; Rodrigo-Moreno et al., 2013; Shen et al., 1997; Tripathy and Oelmüller, 2012).
Plants cope with reactive oxygen stress by increasing the enzymatic and non-enzymatic scavenging activity of ROS, with reactive oxygen itself acting as a signal for inducing defense responses (Gill and Tuteja, 2010; Miller et al., 2010). Nonenzymatic scavengers of reactive oxygen include ascorbic acid, glutathione, phenolic compounds, carotenoids, flavonoids, and tocopherol. Enzymatic scavengers include superoxide dismutase, catalase, glutathione S-transferase, glutathione peroxidase, and ascorbate peroxidase. Salt tolerance in some plants appears to correlate with their ability to scavenge reactive oxygen (de Azevedo Neto et al., 2006; Mittova et al., 2002; Vaidyanathan et al., 2003). Transgenic plants with a high scavenging ability improve salt tolerance (Nagamiya et al., 2007; Yoshimura et al., 2004).

\section{Ion balance}

In plants, $\mathrm{K}^{+}$is the major cellular cation and an essential nutrient. $\mathrm{K}^{+}$is critical for maintaining cell turgor, membrane potential, and membrane integrity and function and for the activity of many enzymes in different pathways (Ashley et al., 2006; Zhu et al., 1998). Excess cytosolic $\mathrm{Na}^{+}$displaces bound $\mathrm{K}^{+}$, leading to a reduced activity of many proteins. Accordingly, supplementing soil or growth media with $\mathrm{K}^{+}$alleviates $\mathrm{NaCl}$ toxicity in plants (Kopittke, 2012). Halophytes attempt to maintain low $\mathrm{Na}^{+}$ concentrations in the cytosol and in general, have evolved $\mathrm{K}^{+}$ uptake systems that lead to efficient $\mathrm{Na}^{+} / \mathrm{K}^{+}$discrimination (Ali et al., 2012). Thus, halophytes may maintain a higher $\mathrm{K}^{+} / \mathrm{Na}^{+}$ ratio than glycophytes.

Potassium uptake is mediated by ion channels and transporters that are distinguished by the levels of selectivity and affinity (Ashley et al., 2006). Their expression is influenced by the severity of stress (Zhu, 2003). High extracellular $\mathrm{Na}^{+}$concentration generally affects $\mathrm{K}^{+}$uptake by low-selectivity sysIn contrast, high-affinity systems continue to operate under $\mathrm{NaCl}$ stress and are important for salt tolerance (Shabala and Cuin, 2007; Szczerba et al., 2009; Zhu, 2003; Zhu et al., 1998). 
$\mathrm{NaCl}$ interferes with $\mathrm{Ca}^{2+}$ uptake and lowers cytosolic $\mathrm{Ca}^{2+}$, which is essential for membrane stability, maintaining osmotic balance, and intracellular signaling (Rengel, 1992). $\mathrm{Ca}^{2+}$ supplementation that restores cytosolic $\mathrm{Ca}^{2+}$ and the growth rate and ameliorates stress symptoms enables the tolerance of higher $\mathrm{NaCl}$ concentrations.

Sequestering excess $\mathrm{NaCl}$ in the vacuole is an important mechanism for establishing ionic balance, thereby reducing the $\mathrm{K}^{+}$concentration required for maintaining turgor. Cytosolic calcium regulates the activity of tonoplast and plasma membranelocalized ion channels (Hedrich and Neher, 1987; Shabala and Cuin, 2007; Zhu, 2007). Calcium also regulates intracellular signaling pathways that lead to the expression of potassium and sodium transporters (Cheong et al., 2003; Ketchum and Poole, 1991; Kim et al., 2007a; Lee et al., 2007). Vacuolar sequestration of $\mathrm{Na}^{+}$is mediated by the action of tonoplastlocalized $\mathrm{Na}^{+} / \mathrm{H}^{+}$antiporters that depend on proton gradients that are generated by tonoplast proton-ATPase and vacuolar pyrophosphatase (Barragán et al., 2012; Jiang et al., 2010; Zhu, 2007). This process is probably more important for halophytes than for glycophytes, given that the former accumulate higher ion concentration in their vacuoles than the latter (Zhu, 2007). In these species, $\mathrm{Na}^{+}$acts as a cheap osmoticum (Adams et al., 1998). In our opinion, such a bulk transport pathway will be discovered in the next decade.

\section{Gene expression of genome structures}

Transcriptome analyses revealed that approximately $30 \%$ of transcriptome is regulated by abiotic stresses (Kreps et al., 2002). Acute stress induces a shared stress response, wherelate responses are largely stress or stimulus specific (Kreps et al., 2002), suggesting that late responses favor adaptation (Sairam and Tyagi, 2004). Not surprisingly, large numbers of early response genes are involved in transcription, membrane transport, phosphoregulation, and immediate ROS defense. Late-response genes specific to $\mathrm{NaCl}$ include a large component involved in redox regulation. A substantial proportion of $\mathrm{NaCl}$-regulated genes are involved in metabolic adjustment and ABA signaling, suggesting that metabolic readjustments are central to $\mathrm{NaCl}$ stress adaptation in Arabidopsis and rice (Kim et al., 2007b; Sahi et al., 2006). NaCl-regulated genes include those involved in the synthesis of osmolytes, defense proteins, and ABA; proteins that protect membranes; proteins that conionic homeostasis such as ion transporters, amino acid transporters, and aquaporins; proteins and small RNAs that control translation; and proteins involved in protein degradation (Sahi et al., 2006; Sunkar et al., 2006). Salt stress tolerance (at least in shock experiments) appears to be decided during the initial phase; although photosynthesis in the salt-tolerant rice line Pokkali declined to one tenth of normal photosynthesis on addition of salt $(150 \mathrm{mM} \mathrm{NaCl})$, the line could recover, grow, and maintain water content in the shoot. However, plants of the saltsensitive line IR19 did not recover and died within a few days after treatment. Moreover, $10 \%$ of tested transcripts in functions relevant to ionic response were up- or downregulated within $1 \mathrm{~h}$ of salt stress in Pokkali, whereas IR29 showed a slower, less pronounced, and incomplete transcriptional response (Kawasaki et al., 2001).

\section{THE SOS PATHWAY}

The SOS signaling pathway regulating ionic homeostasis under salt stress has received much attention, and the functions of the three genes in this pathway have been studied by analyzing
Arabidopsis salt overly sensitive (sos) mutants. The SOS pathway plays an important role in regulating $\mathrm{Na}^{+} / \mathrm{K}^{+}$homeostasis and salt tolerance and includes SOS1, a plasma membranelocalized $\mathrm{Na}^{+} / \mathrm{H}^{+}$antiporter that mediates $\mathrm{Na}^{+}$efflux from the roots and loading of $\mathrm{Na}^{+}$ions in the xylem (Munns, 2002; Olías et al., 2009; Shi et al., 2000; 2002; Zhu, 2003). The second protein component is the Ser/Thr protein kinase SOS2 and the third is the calcium-binding protein SOS3, a myristoylated, EFhand-containing protein. The SOS pathway invokes a salt stress-generated $\mathrm{Ca}^{2+}$ signal that is perceived by SOS3, enabling the formation of the SOS3-SOS2 complex, which phosphorylates and activates the transport activity of SOS1. The activated SOS3-SOS2 complex also stimulates, among other genes, the transcriptional activation of SOS1 and stabilizes cellular levels of SOS1 mRNA (Ji et al., 2013; Zhu, 2003).

The $\mathrm{Ca}^{2+}$-activated SOS pathway directly or indirectly affects $\mathrm{K}^{+}$homeostasis. sos 1 , sos2, and $\operatorname{sos} 3$ mutants are hypersensitive to $\mathrm{K}^{+}$deficiency. However, activated SOS1 does not transport $\mathrm{K}^{+}$(Quintero et al., 2002). $\mathrm{K}^{+}$uptake in sos mutants is inhibited by even mild $\mathrm{NaCl}$ stress. The activity of ARABIDOPSIS K TRANSPORTER1 (AKT1), a major highly selective potassium channel mediating potassium uptake under low $\mathrm{K}^{+}$conditions, is inhibited by high cytoplasmic $\mathrm{NaCl}$ concentratiosn (Pyo et al., 2010; Qi and Spalding, 2004), suggesting that the SOS pathway is affected by the activity of AKT1. Some mutations and deletions of the $\mathrm{Na}^{+}$-transporter HKT1 suppress the salt-hypersensitive phenotype of sos mutants by inhibiting the accumulation of $\mathrm{Na}^{+}$. Hypersensitivity to $\mathrm{K}^{+}$deficiency of the sos mutants was suppressed by the expression of mutated HKT1 (Rus et al., 2001; 2004). The SOS pathway is also suggested to mediate salt tolerance by modulating the activity of vacuolar $\mathrm{H}^{+}$-ATPase (V-ATPase), which is both tonoplast and endosome localized. SOS2 binds to regulatory subunits of $\mathrm{V}$ ATPase and stimulates its activity (Batelli et al., 2007). An endosomal V-ATPase mediates salt tolerance (Krebs et al., 2010) Finally, the SOS pathway controls endocytosis, vacuolar shape and function, and intracellular $\mathrm{pH}$ (Oh et al., 2010), although the mechanisms by which this is accomplished are unknown.

The SOS pathway genes are conserved in many plant species (Martínez-Atienza et al., 2007; Olías et al., 2009; Tang et al., 2010; Wu et al., 2007; Xu et al., 2008) and their overexpression increases salt tolerance in Arabidopsis and in heterologous species (Shi et al., 2003; Yang et al., 2009; Zhang and Blumwald, 2001; Zhang et al., 2009). SOS1 mRNA is unstable under normal growth conditions but is stabilized by salt (ionic) and dehydration stresses (Chung et al., 2008; Shi et al., 2003). The stabilization of SOS1 mRNA is also mediated by reactive oxygen species with SOS1, a component in oxidative stress signaling (Chung et al., 2008; Katiyar-Agarwal et al., 2006). SOS2 may also participate in reactive oxygen signaling (Verslues et al., 2007).

\section{HORMONE-MEDIATED RESPONSES TO SALT STRESS}

\section{ABA pathways in stress response pathways}

The synthesis, sequestration, transportation, and turnover of numerous metabolites with hormone character generates a web of signals that correlate plant growth, flowering, and seed production in dependence on internal and external cues. Among these hormones, ABA is of particular importance for stress recognition and stress defense reactions. ABA signaling cascades, synchronized with the plant growth stage and other hormone levels, regulate important abiotic stress responses, in particular water balance and osmotic stress tolerance. Guard 
cell movement that is regulated by $\mathrm{ABA}$ leads to stomatal closure as an immediate response to ion imbalance and water deficit. Furthermore, ABA induces the synthesis of dehydration tolerance proteins with general metabolic adjustments.

ABA biosynthesis genes and ABA accumulation are upregulated by $\mathrm{NaCl}$, drought, or cold stress (Cheong and Yun, 2007; Umezawa et al., 2006; Zhang et al., 2006; Zhu, 2002). Although $A B A$, produced in roots in response to dehydration, is transported to the leaves via the xylem, it is believed that $A B A$ produced de novo in various plant organs is more important for physiological responses (Seung et al., 2012).

\section{Other hormones and hormone balance}

ABA-independent pathways for regulating gene expression in response to salinity, drought, and cold stress also exist (Cheong and Yun, 2007; Sairam and Tyagi, 2004). For example, brassinosteroids increase tolerance to stresses, including salinity, by mediating the synthesis of enzymatic or nonenzymatic antioxidant systems, proline, or lectins (Bajguz and Hayat, 2009). Although salicylic acid (SA), another growth mediator, generates ROS that may negatively affect the salt stress response (Barba-Espín et al., 2011; Hao et al., 2012), it can alleviate salt-induced oxidative stress through the MAPK pathway when externally applied at a sublethal level. The SA effect reduces salt-induced membrane depolarization (Gémes et al., 2011; Horváth et al., 2007; Jayakannan et al., 2013; Opdenakker et al., 2012; Rivas-San Vicente and Plasencia, 2011; Yuan and Lin, 2008). Furthermore, salt alters the expression of auxinresponsive genes and auxin/IAA pathways in different plants (Jain and Khurana, 2009; Liu et al., 2013b; Wang et al., 2010). The model legume Medicago truncatula exhibits a higher tolerance to $300 \mathrm{mM} \mathrm{NaCl}$ treatment when indole-3-acetic acidoverproducing Sinorhizobium meliloti are present (Bianco and Defez, 2009). In addition, the polar distribution of auxin appears to be important for oxidative stress responses because auxin transporter mutants, such as aux1, pin1, and pin2, are hypersensitive to arsenite-induced oxidative stress compared with the auxin transporter wild-type (Krishnamurthy and Rathinasabapathi, 2013).

Ethylene and gibberellin (GA) signaling have been observed in salt stress responses. The bioactive GA amount is reduced on salt treatment in the wild-type. A ga1-3 mutant lacking entcopalyl diphosphate synthase, the first committed step enzyme in GA biosynthesis, is tolerant to salt. A quadruple DELLA mutant defective in genes associated with the GA pathway, lacking $G A I, R G A, R G L 1$, and $R G L 2$, is less tolerant to salt treatment compared with the wild-type at high salt concentrations (Achard et al., 2006). Delay in flowering by salt is reduced in the quadruple DELLA mutant and GA-induced DELLA degradation is inhibited by ABA (Achard et al., 2006). spy, a loss of function mutation in SPINDLY (SPY), encoding an O-linked $\mathrm{N}$-acetylglucosamine transferase, exhibits higher expression of $\mathrm{GA}$ responsive genes, suggesting that SPY represses GA signaling (Olszewski et al., 2002; 2010; Qin et al., 2011). spy is tolerant to salt and drought stresses, wherein stress responsive genes, such as RD20, ABSCISIC ACID RESPONSIVE ELEMENTSBINDING FACTOR 1-like transcription factor, and late embryogenesis-abundant proteins, are upregulated (Qin et al., 2011).

Ethylene is sensed by ENDOPLASMIC RETICULUMmembrane proteins and receptors, including ETHYLENE RESPONSE (ETR)1, ETR2, ETHYLENE RESPONSE SENSOR (ERS)1, ERS2, and ETHYLENE INSENSITIVE (EIN)4. Under normal conditions, the receptors of ethylene, which are characterized by low ethylene levels, bind to and activate the negative regulator of ethylene signaling, CONSTITUTIVE TRIPLE RESPONSE1 (CTR1), a Raf-like MITOGEN-ACTIVATED PROTEIN KINASE KINASE KINASE. ER-integrated EIN2, which is downstream of CTR1, is a positive transducer of ethylene signaling whose stability is regulated by two F-box proteins EIN2-TARGETING PROTEIN and 26S proteasomemediated degradation. Plants emanate ethylene gas on salt treatment (Achard et al., 2006). Treatment with ACC, a substrate of ethylene synthesis, increases tolerance to high salt. Similarly, the ctr1-1 mutant, which displays constitutive ethylene responses on EIN3 accumulation, exhibits higher tolerance (Achard et al., 2006; Cao et al., 2007b). Mutations in ACS7 (ACC synthase) reduce ethylene emission compared with the wild-type and enhance tolerance to salt, osmotic, and heat stresses because of the upregulated expression of stress responsive ABA-dependent genes (Dong et al., 2011).

\section{Developmental changes}

Senescence, in particular leaf senescence, constitutes a regulated developmental process that coordinates metabolite redistribution, reproductive maturation, and programmed cell death. Senescence is affected by endogenous factors, responding to environmental signals. The endogenous factors include plant growth stage and phytohormonal levels, which are influenced by many adverse environmental conditions such as drought, nutrient limitation, heat, ozone, and UV irradiation (Jibran et al., 2013; Lim et al., 2007; Munné-Bosch and Alegre, 2004). For example, two ethylene-insensitive mutants etr1 and ein2 exhibit inhibited seed germination, enhanced leaf cell expansion, delayed flowering, and acceleration of senescence (Bleecke and Patterson, 1997; Kende and Zeevaart, 1997), thereby implicating ethylene during organ shedding. A group of senescenceassociated genes (SAGs) is involved in nutrient recycling and transport and detoxification (Gepstein et al., 2003; Lim et al., 2007). Responses that affect stress tolerance include functions of the NAC transcription factor ANAC092/AtNAC2/ORE1 and the senescence-associated protein SAG29 that are related to salinity stress responses (Balazadeh et al., 2010; Seo et al., 2011). SAG29 gene expression is induced by abiotic stresses such as cold, $\mathrm{NaCl}$, drought, and ABA treatment. A loss-offunction mutation in SAG29 is less sensitive to salt compared with the wild-type, whereas transgenic overexpression of SAG29 results in high sensitivity to salt and also early senescence (Seo et al., 2011).

\section{CIRCADIAN CLOCK RESPONSES TO ENVIRONMENTAL STRESS}

The circadian clock controls the 24-h biological rhythms or oscillations, resulting from the rotation of the earth (refer to Harmer, 2009; McClung, 2011 for detailed information about the circadian clock). In plants, the circadian clock entrains a plant's memory and anticipation of the progression of time or predictable and daily changes (McClung and Davis, 2010; Sanchez et al., 2011). The plant clock is involved in plant biological processes, such as stomatal dynamics, shade avoidance, and metabolic activity, and in defenses against pathogens and in abiotic stress responses (Covington et al., 2008; Dalchau et al., 2011; Dodd et al., 2005a; Graf et al., 2010; Harmer et al., 2000; Hong et al., 2013; Hotta et al., 2007; Kreps et al., 2002; Seung et al., 2012; Wang et al., 2011). Levels of the stress hormone $A B A$ in leaves and ABA biosynthesis, conjugation, and turnover exhibit diurnal oscillations (Seung et al., 2012). Transcript levels of genes involved in $\mathrm{ABA}$ sensing, core signaling, and signal 
transduction exhibit diurnal oscillations, indicating gating by the clock (Legnaioli et al., 2009). Similarly, cyclic oscillations in cytosolic $\mathrm{Ca}^{2+}$ levels are under the circadian clock control (Dodd et al., 2005b; 2007; Xu et al., 2007; 2009). In addition, a large number of salt-, dehydration-, and osmotic stressregulated or -responsive genes are under the circadian clock control (Covington et al., 2008; Harmer et al., 2000; Kreps et al., 2002). Gene expression at the transcription level with respect to drought responses is gated by the circadian clock (Wilkins et al., 2010). Genes, such as SOS1, RD29A, and DREB2A, that are involved in salinity stress exhibit a 24-h period of expression (diurnal web; http://diurnal.mocklerlab.org/), suggesting that salt tolerance may also be affected by the circadian clock. Moreothe circadian clock modulates the cold signaling pathway (Dodd et al., 2006). Cold-induced expression of the C-repeat binding factor/dehydration-responsive element binding factor (CBF/DREB) genes CBF1/DREB1B, CBF2/DREB1C, and CBF3/DREB1A is dependent on the time of day at which the plants are exposed to low temperature (Fowler et al., 2005).

\section{Molecular mechanisms of the plant circadian clock responsive to environmental stress}

The manner in which temporal information is passed from the clock to various plant processes is only partially understood. At the molecular level, four mechanisms appear to be involved (Thines and Harmon, 2011).

First, core clock proteins, such as CCA1, LHY and TOC1, have been demonstrated to directly bind to regulatory regions of the output genes, and thus, confer rhythmicity on their transcription (Barajas-López et al., 2011; Legnaioli et al., 2009; Maxwell et al., 2003; Schaffer et al., 1998; Wang et al., 1997). Accumulating genetic evidence indicates altered transcription of genes after core components of the clock have been deleted or altered in their expression (Blázquez et al., 2002; Michael et al., 2008; Thain et al., 2004).

Second, clock-controlled rhythmic chromatin modifications that lead to the modifications of gene expression are widespread in mammalian systems (e.g., Etchegaray et al., 2003). The acetylation of HISTONE3 in nucleosomes associated with the TOC1 promoter has been observed, and the inhibition of this acetylation by CCA1 affects the rhythmic TOC1 expression (Perales and Más, 2007). It appears likely that the clock controls the rhythmic chromatin modification of other genes as well. Third, the clock imposes a rhythmic expression on a large number of transcription factors (Covington and Harmer, 2007; Covington et al., 2008; Harmer et al., 2000). For example, enzymes involved in auxin biosynthesis and auxin-inducible genes for auxin signal transduction or auxin sensitivity are under the clock control (Covington and Harmer, 2007). Coldinduced COR15b and DREB1a/CBF3 are clock controlled (Harmer et al., 2000).

The fourth mechanism has been recently researched and defines the physical interaction of core clock proteins with proteins associated with other pathways. To a large degree, such an interaction controls the availability or/and stability of clock components. TOC1 interacts with proteins that do not function in the clock core but affect the clock output. For example, TOC1 interacts with the PHYTOCHROME INTERACTING FACTOR 7 (PIF7), thus controlling the time of CBF2/DREB1C expression (Kidokoro et al., 2009). PIF7 binds to the promoter of CBF2 and represses its expression. Interaction with TOC1 and phyB increases the repressive activity of PIF7. As the CBF genes play protective roles at a low temperature, TOC1-PIF7 and PHYBPIF7 interactions reduce $C B F$ expression at higher daytime temperatures but enable the expression at lower temperatures during the night. TOC1 also interacts with PHYTOCHROME INTERACTING FACTOR LIKE 1, and both proteins are necessary for rapid growth during shade avoidance (Salter et al., 2003). The ABA-associated gene $A B A R / C H L H / G U N 5$, which is considered to be a plastid receptor for $A B A$ that mediates $A B A$ downstream signaling, interacts with TOC1 (Legnaioli et al., 2009; Wang and Zhang, 2008). Although GIGANTEA (GI, see below) appears to mediate cold stress response by a $C B F$ independent pathway (Cao et al., 2005), the TOC1 homoloPRR5, 7, and 9 genes (Farré et al., 2005; Fujimori et al., 2005; Kim et al., 2010; Nakamichi et al., 2005a; 2005b; Salomé and McClung, 2005) have redundant functions in regulating the transcription of cold stress response genes through the DREB1/CBF pathway (Nakamichi et al., 2009).

Integration of GI in diverse environmental stresses

The clock component GI is linked to several clock output components, such as photoperiod control of flowering, PhyB signaling, circadian clock, and carbohydrate metabolism. The gi mutant exhibits light-dependent resistance to paraquat-induced oxidative stress, possibly because of high superoxide dismutase and ascorbate peroxidase (Cao et al., 2006; Kurepa et al., 1998). The gi mutant with a longer hypocotyl than the wildtype under constant red light suggests a Gl involvement in PhyB signaling (Huq et al., 2000). The gi mutant is sensitive to cold and freezing and shows reduced amounts of cold-induced sugars and high starch accumulation (Cao et al., 2005; 2007a; Eimert et al., 1995). Gl appears to independently mediate a cold stress response of the CBF-mediated cold stress pathway (Cao et al., 2005). In addition, the gi mutants lose the drought escape response, which is the ability of plants to complete their life cycle before stress conditions result in death (Riboni et al., 2013).

$\mathrm{Gl}$ is a large nucleoplasmatic protein that is encoded by a conserved single gene in most plant species (Fowler et al., 1999; Huq et al., 2000; Mizoguchi et al., 2005; Park et al., 1999). Circadian GI transcription appears to be positively regulated by temperature and light (Paltiel et al., 2006). In addition, $\mathrm{Gl}$ is transcriptionally induced by cold stress but not by salt, mannitol, or ABA.

GI transcription is under the circadian control and peaks at 8$10 \mathrm{~h}$ after the start of the day. The Gl protein amount or abundance, which is controlled by dark-induced proteolysis, closely follows this behavior (David et al., 2006). The amplitude, timing, and duration of this peak depend on the day length (Fowler et al., 1999). Mutational inactivation of $G /$ alters the expression pattern with respect to amplitude and period length of two circadian oscillator genes CCA1 and LHY. The loss of function in $\mathrm{Gl}$ also incurs defectiveness in light signaling to the clock. The light-regulated association of Gl with the light-sensing F-box protein ZEITLUPE is responsible for dark-dependent proteasomal degradation of TOC1, which reduces the transcription of CCA1 and LHY (Kim et al., 2007c; Mas et al., 2003). Mutational inactivation of $\mathrm{Gl}$ also affects clock outputs, leading to late flowering in long days but having little or no effect in short days (Fowler et al., 1999). The Gl protein forms a protein complex with the blue-light sensing FLAVIN-BINDING, KELCH REPEAT, F-BOX 1 (FKF1), which targets and degrades CYCLING DOF FACTOR 1 (CDF1), a repressor of the transcription of CONSTANS (CO) (Sawa et al., 2007). The precise timing of the expression of $C O$ is necessary for daylength discrimination and photoperiodic flowering (Fig. 2A). Gl directly promotes FT as well (Sawa and Kay, 2011). 
A

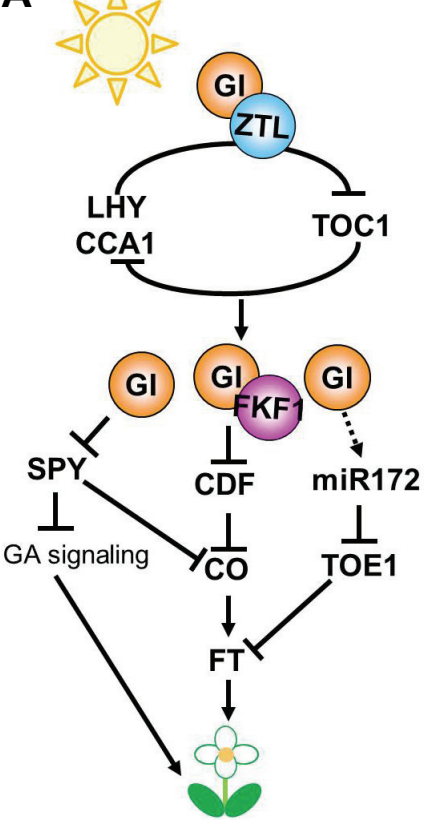

B

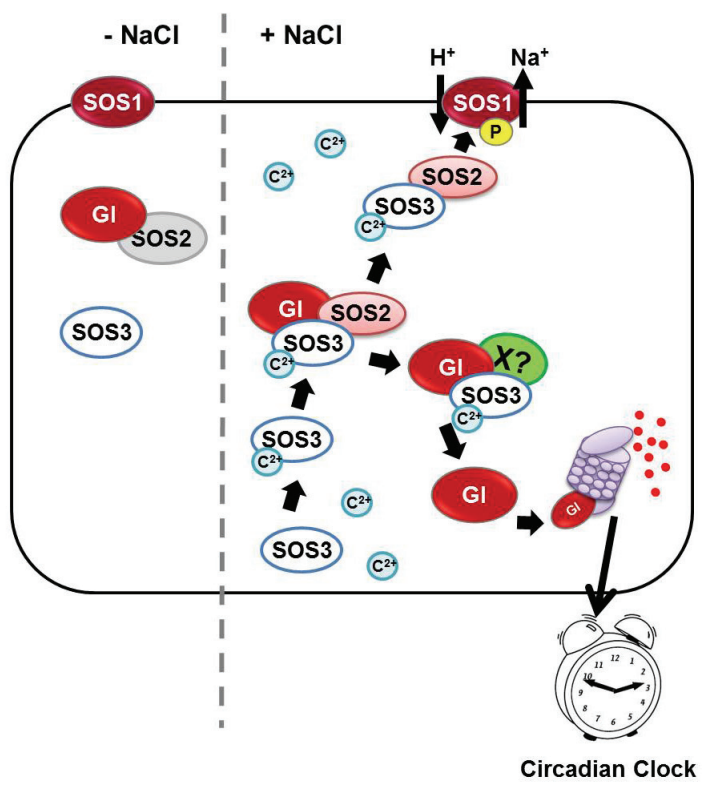

Fig. 2. GIGANTEA (GI) regulates flowering in a long day $(A)$ and salt stress (B) response. (A) Gl forms a complex with FKF1, which degrades CDF1, a repressor of $C O$, a central activator of photoperiodic flowering. Furthermore, Gl independently promotes flowering of $\mathrm{CO}$ through miR172. miRNA172 targets AP2-like genes, such as TOE1, which negatively regulates multiple floral organ identity. SPY is considered a negative regulator of GA and positively promotes flowering during long days. (B) Salt-dependent interaction between $\mathrm{Gl}$ and SOS2 (Kim et al., 2013). SOS2 and GI form a complex in unstressed plants. This complex prevents the interaction of SOS2 with SOS1; thus, SOS1 is kept in an inactive state. On salinity stress, the elevation of cellular $\mathrm{Na}^{+}$triggers a salt stress-specific calcium signature, which is recognized by a calciumbinding protein, SOS3. SOS2 binds to calcium-bound SOS3, releasing the

GI protein, which then is degraded. In turn, the free SOS2/SOS3 complex activates SOS1, a $\mathrm{Na}^{+} / \mathrm{H}^{+}$antiporter, and sodium ( $\mathrm{Na}^{+}$) ions are exported from the cells.

Another mechanism through which GI influences photoperiodic flowering involves the induction of $F T$ independently from $\mathrm{CO}$. This induction is accomplished by regulating miR172 processing, which affects miR172 abundance (Jung et al., 2007). miR172 targets and represses APETALA2-like genes such as TARGET OF EAT1 (TOE1), TOE2, and TOE3 (Fig. 2A) (Aukerman and Sakai, 2003). Gl and ELF4 regulate hypocotyl growth in response to daylength in a light-phase-specific manner (Kim et al., 2012). Furthermore, Gl is involved in phyB and cryptochrome signaling (Crepy et al., 2007; Huq et al., 2000; Oliverio et al., 2007). Regulating Gl expression depending on sucrose levels is also important, suggesting a link that measures and reports metabolic status to alter or reset the circadian clock (Dalchau et al., 2011).

SPINDLY, an O-linked $\beta$-N-acetylglucosamine transferase that acts as a negative regulator of GA signaling, participates in protein-protein interactions with $\mathrm{Gl}$, thereby acting as a negative regulator of salt stress response (Kim et al., 2013; Tseng et al., 2004). This specific two-protein interaction regulates the flowering time and circadian stomatal dynamics (Fig. 2A) (Sothern et al., 2002; Tseng et al., 2004).

\section{Function of $\mathrm{Gl}$ in response to salt stress}

Recently, an association between $\mathrm{Gl}$ and $\mathrm{NaCl}$ and/or osmotic stresses has emerged (Kim et al., 2013; Park et al., 2013) that helps in identifying the direct regulation of ionic homeostasis through GI. GI is a partner in a protein-protein interaction with the SNF1-related protein kinase SOS2, a known key element of the SOS pathway. This interaction strongly reduces or prevents the main function of SOS2, i.e., the activation of the SOS1 antiporter under normal, nonstressed growth conditions. Salt stress induces or increases proteasomal degradation of GI, thus releasing the SOS2 protein, which then interacts with the SOS3 protein (Fig. 2B). This process of SOS2 caging and release is reflected in the corresponding phenotypes. Gl-overexpressing plants are more salt sensitive than wild-type plants, whereas the gi mutants are markedly salt tolerant. Incidentally, this observation strongly supports the notion that salt-induced activation of the SOS2 kinase promotes the phosphorylation and activation of the $\mathrm{Na}^{+} / \mathrm{H}^{+}$antiporter SOS1. Thus Gl introduces another player underlying the dynamic behavior of SOS2 via its stress-induced release from interaction with GI. The presence or amount of $\mathrm{Gl}$ and its degradation associate salt stress to the clock functions, thus associating pathways previously considered unrelated.

Yet another remarkable aspect of the salt-tolerant phenotype exhibited by gi plants is continued growth under high salinity. This behavior appears to indicate arrest in the vegetative growth phase during stress. The plants produce many more leaves than the wild-type Arabidopsis and exhibit extremely late flowering. This behavior may be the result of hierarchically structured responses governing salt exclusion, salt export, and salt compartmentalization in a mode that is growth-phase specific, while at the same time influencing growth phase transitions associated to the working of the clock. An appropriate and effective stress response appears to require an evolutionary history that entrains a series of interactive signaling and response measures based on changes in the environment. Such changes may not have been essential for most plant species.

\section{CONCLUSION}

Salinity in natural settings, such as in estuaries; intrusion of brackish water from the sea; or salinization after the depletion of fresh water in aquifers is a common terrestrial feature. In lands under cultivation, the inevitable accumulation of salts during long-term irrigation remains to be studied. Humanity's influence will, again inevitably, require that at least some food 
and feed be produced on degraded soils, including saline lands. All plants likely carry the genes that must be engaged to deal with salinity, but salinity tolerance acquisition requires modifications and alterations in their genomes. Similarly, the development of control structures, which engage these genes in a meaningful way and lead to protection, appears to be lacking in many plant species that are evolved in areas in which $\mathrm{Na}^{+}$was low.

Previous studies have led to the recognition of likely most of the important stress defense components. Most appear to be the same or are very similar components in most species. Furthermore, we have very little knowledge regarding how the many different constituent proteins are generated by only partially outlined transcriptional programs and where they are located in plant organs and cells and how they are expressed in a developmental context. Equally, we do not know the dynamics of subcellular trafficking that accompanies adaptations to a stressful environment.

However, the appearance of next-generation DNA and RNA sequencing tools has generated genome sequences from species that were adapted to stressful environments (Dassanayake et al., 2011; Ma et al., 2013; Wu et al., 2012) and sequences for species in the genus Arabidopsis and $A$. thaliana ecotypes adapted to different ecological niches and lifestyles (Hanikenne et al., 2013; Hollister et al., 2012; Kellermeier et al., 2013; Weigel, 2012). We can now compare entire genomes at a chromosomal resolution, and we can add in unprecedented completeness, the transcriptomes of entire plants, plant organs, and cells under every conceivable external stimulus/stress.

Several initial analyses are currently available. Dassanyake et al. (2011) and Wu et al. (2012) compared the salt tolerant extremophiles $S$. parvula and $T$. salsuginea, respectively, to the genome of $A$. thaliana, a close relative in the Brassicaceae. The results may be summarized by three statements. First, at a genome sequence level, the distinguishing character of halophytes is the presence of gene duplications in functions that support salt tolerance. In addition, translocations of genes are found in halophytes that appear to have changed their expression. It is important to state that Arabidopsis shows approximately as many gene duplications in total as halophytes; however, those that are retained functions in biotic and not abiotic functions of stress protection. A recent study comparing two differently salt-tolerant poplar species reported very similar gene duplication events (Ma et al., 2013). The second statement is regarding gene transcription. Halophytes generally demonstrate higher expression levels of (known) stressrelevant genes even in the absence of a stress; however, stress may lead to an extremely high additional expression that is not observed in Arabidopsis. Moreover, comparisons of these genomes reveal extensive sequence changes in the presumptive promoter regions of differentially expressed transcripts, although no detailed analyses have been reported to date. The final statement is regarding the changes in the protein coding regions. Although differences are documented, it is largely unknown whether such changes impart qualities that support stress tolerance; for example, one of the duplicated HKT1 genes in T. salsuginea (Ali et al., 2012). A single amino acid exchange converts this cation transporter from mainly transporting $\mathrm{Na}^{+}$in highly saline media, as observed in $A$. thaliana, to a mainly $\mathrm{K}^{+}$-importing protein in $T$. salsuginea. In addition, belonging in this category are observations indicating coding regions with altered domain structure and differently spliced transcripts in comparison with related salt-sensitive species.

Understanding plant salinity stress defense or avoidance mechanisms is a key challenge for improving crop breeding.
Even with the progress that is currently possible, the pathways for salt exclusion, compartmentation, and efflux are exceedingly complex. Screening crops, wide crosses of crops, and their wild relatives for gene duplication and stress-relevant expression characteristics should be one way forward. Much emphasis should be placed on obtaining more detailed information regarding plant hormone synthesis, transport, and perception and regarding its associated signaling systems that orchestrate growth under stress.

\section{ACKNOWLEDGMENTS}

This study was supported by grants from the National Research Foundation of Korea (NRF) funded by the Korean Government (MSIP No. 2016R1A2A1A05004931) and NextGeneration BioGreen21 Program (SSAC, grant\#: PJ01105101) Rural Development Administration, Republic of Korea. H.J. Park was supported by the Basic Science Research Program through NRF funded by the Ministry of Science, ICT \& Future Planning (NRF-2013R1A1A3013245). We thank Hans J. Bohnert for reading the manuscript and discussions.

\section{REFERENCES}

Achard, P., Cheng, H., De Grauwe, L., Decat, J., Schoutteten, H., Moritz, T., Van Der Straeten, D., Peng, J., and Harberd, N.P. (2006). Integration of plant responses to environmentally activated phytohormonal signals. Science 311, 91-94.

Adams, P., Nelson, D.E., Chmara, W., Bohnert, H.J., and Griffiths H. (1998). Growth and development of Mesembryanthemum crystallinum (Aizoaceae). New Phytol. 138, 171-190.

Ali, Z., Park, H.C., Ali, A., Oh, D.-H., Aman, R., Kropornicka, A., Hong, H., Choi, W., Chung, W.S., Kim, W.-Y., et al. (2012). TsHKT1;2, a HKT1 homolog from the extremophile Arabidopsis relative Thellungiella salsuginea, shows $\mathrm{K}^{+}$specificity in the presence of $\mathrm{NaCl}$. Plant Physiol. 158, 1463-1474.

Andres, F., and Coupland, G. (2012). The genetic basis of flowering responses to seasonal cues. Nat. Rev. Genet. 13, 627-639.

Ashley, M.K., Grant, M., and Grabov, A. (2006). Plant responses to potassium deficiencies: a role for potassium transport proteins. J. Exp. Bot. 57, 425-436.

Aukerman, M. J., and Sakai, H. (2003). Regulation of flowering time and floral organ identity by a microRNA and its APETALA2-like target genes. Plant Cell 15, 2730-2741.

de Azevedo Neto, A.D., Prisco, J. T., Enéas-Filho, J., Abreu, C.E.B. de, and Gomes-Filho, E. (2006). Effect of salt stress on antioxidative enzymes and lipid peroxidation in leaves and roots of salttolerant and salt-sensitive maize genotypes. Env. Exp. Bot. 56, 87-94.

Bajguz, A., and Hayat, S. (2009). Effects of brassinosteroids on the plant responses to environmental stresses. Plant Physiol. Biochem. 47, 1-8.

Balazadeh, S., Siddiqui, H., Allu, A.D., Matallana-Ramirez, L.P., Caldana, C., Mehrnia, M., Zanor, M.--., Köhler, B., and MuellerRoeber, B. (2010). A gene regulatory network controlled by the NAC transcription factor ANAC092/AtNAC2/ORE1 during saltpromoted senescence. Plant J. 62, 250-264.

Barajas-López, J. de D., Serrato, A.J., Cazalis, R., Meyer, Y., Chueca, A., Reichheld, J.P., and Sahrawy, M. (2011). Circadian regulation of chloroplastic $f$ and $m$ thioredoxins through control of the CCA1 transcription factor. J. Exp. Bot. 62, 2039-2051.

Barba-Espín, G., Clemente-Moreno, M.J., Álvarez, S., GarcíaLegaz, M.F., Hernández, J.A., and Díaz-Vivancos, P. (2011). Salicylic acid negatively affects the response to salt stress in pea plants. Plant Biol. 13, 909-917.

Barragán, V., Leidi, E.O., Andrés, Z., Rubio, L., De Luca, A., Fernández, J.A., Cubero, B., and Pardo, J.M. (2012). Ion exchangers NHX1 and NHX2 mediate active potassium uptake into vacuoles to regulate cell turgor and stomatal function in Arabidopsis. Plant Cell 24,1127-1142.

Batelli, G., Verslues, P.E., Agius, F., Qiu, Q., Fujii, H., Pan, S. Schumaker, K.S., Grillo, S., and Zhu, J.-K. (2007). SOS2 pro- 
motes salt tolerance in part by interacting with the vacuolar $\mathrm{H}^{+}$ATPase and upregulating its transport activity. Mol. Cell Biol. 27, 7781-7790.

Bendix, C., Mendoza, J.M., Stanley, D.N., Meeley, R., and Harmon, F.G. (2013). The circadian clock-associated gene gigantea1 affects maize developmental transitions. Plant Cell Environ. 36, 1379-1390.

Bianco, C., and Defez, R. (2009). Medicago truncatula improves salt tolerance when nodulated by an indole-3-acetic acidoverproducing Sinorhizobium meliloti strain. J. Exp. Bot. 60, 3097-3107.

Black, R. (1960). Effects of naci on the ion uptake and growth of Atriplex vesicaria Heward. Aust. J. Biol. Sci. 13, 249-266.

Blázquez, M.A., Trénor, M., and Weigel, D. (2002). Independent control of gibberellin biosynthesis and flowering time by the circadian clock in Arabidopsis. Plant Physiol. 130, 1770-1775.

Bleecke, A.B., and Patterson, S.E. (1997). Last exit: senescence, abscission, and meristem arrest in Arabidopsis. Plant Cell 9, 1169-1179.

Blokhina, O., Virolainen, E., and Fagerstedt, K.V. (2003). Antioxidants, oxidative damage and oxygen deprivation stress: a review. Ann. Bot. 91, 179-194.

Bohnert, H.J., and Jensen, R.G. (1996). Strategies for engineering water-stress tolerance in plants. Trends Biotechnol. 14, 89-97.

Bohnert, H.J., and Cushman, J.C. (2000). The ice plant cometh: lessons in abiotic stress tolerance. J. Plant Growth Regul. 19, 334-346.

Bohnert, H.J., Nelson, D.E., and Jensen, R.G. (1995). Adaptations to environmental stresses. Plant Cell 7, 1099-1111.

Cao, S., Ye, M., and Jiang, S. (2005). Involvement of GIGANTEA gene in the regulation of the cold stress response in Arabidopsis. Plant Cell Rep. 24, 683-690.

Cao, S., Jiang, S., and Zhang, R. (2006). The role of GIGANTEA gene in mediating the oxidative stress response and in Arabidopsis. Plant Growth Regul. 48, 261-270.

Cao, S.Q., Song, Y.Q., and Su, L. (2007a). Freezing sensitivity in the gigantea mutant of Arabidopsis is associated with sugar deficiency. Biol. Plant 51, 359-362.

Cao, W.-H., Liu, J., He, X.-J., Mu, R.-L., Zhou, H.-L., Chen, S.-Y., and Zhang, J.-S. (2007b). Modulation of ethylene responses affects plant salt-stress responses. Plant Physiol. 143, 707-719.

Cheong, M., and Yun, D.-J. (2007). Salt-stress signaling. J. Plant Biol. 50, 148-155

Cheong, Y.H., Kim, K.-N., Pandey, G.K., Gupta, R., Grant, J.J., and Luan, S. (2003). CBL1, a calcium sensor that differentially regulates salt, drought, and cold responses in Arabidopsis. Plant Cell 15, 1833-1845.

Chung, J.-S., Zhu, J.-K., Bressan, R.A., Hasegawa, P.M., and Shi, H. (2008). Reactive oxygen species mediate $\mathrm{Na}^{+}$-induced SOS1 mRNA stability in Arabidopsis. Plant J. 53, 554-565.

Covington, M.F., and Harmer, S.L. (2007). The circadian clock regulates auxin signaling and responses in Arabidopsis. PLoS One 5, e222.

Covington, M., Maloof, J., Straume, M., Kay, S., and Harmer, S. (2008). Global transcriptome analysis reveals circadian regulation of key pathways in plant growth and development. Genome Biol. 9, R130.

Craig Plett, D., and Møller, I.S. (2010). $\mathrm{Na}^{+}$transport in glycophytic plants: what we know and would like to know. Plant Cell Env. 33, 612-626

Cramer, G.R., and Jones, R.L. (1996). Osmotic stress and abscisic acid reduce cytosolic calcium activities in roots of Arabidopsis thaliana. Plant Cell Env. 19, 1291-1298.

Crepy, M., Yanovsky, M.J., and Casal, J.J. (2007). Blue rhythms between GIGANTEA and phytochromes. Plant Signal. Behav. 2, 530-532.

Dalchau, N., Baek, S.J., Briggs, H.M., Robertson, F.C., Dodd, A.N., Gardner, M.J., Stancombe, M.A., Haydon, M.J., Stan, G.-B., Gonçalves, J.M., et al. (2011). The circadian oscillator gene GIGANTEA mediates a long-term response of the Arabidopsis thaliana circadian clock to sucrose. Proc. Natl. Acad. Sci. USA $108,5104-5109$

Dassanayake, M., Oh, D.-H., Haas, J.S., Hernandez, A., Hong, H., Ali, S., Yun, D.-J., Bressan, R.A., Zhu, J.-K., Bohnert, H.J., et al. (2011). The genome of the extremophile crucifer Thellungiella parvula. Nat Genet. 43, 913-918.
David, K.M., Armbruster, U., Tama, N., and Putterill, J. (2006). Arabidopsis GIGANTEA protein is post-transcriptionally regulated by light and dark. FEBS Lett. 580, 1193-1197.

DeWald, D.B., Torabinejad, J., Jones, C.A., Shope, J.C., Cangelosi, A.R., Thompson, J.E., Prestwich, G.D., and Hama, H. (2001). Rapid accumulation of phosphatidylinositol 4,5-bisphosphate and inositol 1,4,5-trisphosphate correlates with calcium mobilization in salt-stressed Arabidopsis. Plant Physiol. 126, 759-769.

Dietz, K.-J. (2003). Plant peroxiredoxins. Annu. Rev. Plant Biol. 54, 93-107.

Dodd, A.N., Salathia, N., Hall, A., Kévei, E., Tóth, R., Nagy, F., Hibberd, J.M., Millar, A.J., and Webb, A.A.R. (2005a). Plant circadian clocks increase photosynthesis, growth, survival, and competitive advantage. Science 309, 630-633.

Dodd, A.N., Love, J., and Webb, A.A.R. (2005b). The plant clock shows its metal: circadian regulation of cytosolic free $\mathrm{Ca}^{2+}$. Trends Plant Sci. 10, 15-21.

Dodd, A.N., Jakobsen, M.K., Baker, A.J., Telzerow, A., Hou, S.-W., Laplaze, L., Barrot, L., Scott Poethig, R., Haseloff, J., and Webb, A.A.R. (2006). Time of day modulates low-temperature $\mathrm{Ca}^{2+}$ signals in Arabidopsis. Plant J. 48, 962-973.

Dodd, A.N., Gardner, M.J., Hotta, C.T., Hubbard, K.E., Dalchau, N., Love, J., Assie, J.-M., Robertson, F.C., Jakobsen, M.K., Goncalves, J., et al. (2007). The Arabidopsis circadian clock incorporates a cADPR-based feedback loop. Science 318, 1789-1792.

Dong, H., Zhen, Z., Peng, J., Chang, L., Gong, Q., and Wang, N.N. (2011). Loss of ACS7 confers abiotic stress tolerance by modulating $\mathrm{ABA}$ sensitivity and accumulation in Arabidopsis. J. Exp. Bot. 62, 4875-4887.

Ducrocq, S., Madur, D., Veyrieras, J.-B., Camus-Kulandaivelu, L., Kloiber-Maitz, M., Presterl, T., Ouzunova, M., Manicacci, D., and Charcosset, A. (2008). Key impact of Vgt1 on flowering time adaptation in maize: Evidence from association mapping and ecogeographical information. Genetics 178, 2433-2437.

Eimert, K., Wang, S.M., Lue, W.I., and Chen, J. (1995). Monogenic recessive mutations causing both late floral initiation and excess starch accumulation in Arabidopsis. Plant Cell 7, 1703-1712.

Etchegaray, J.-P., Lee, C., Wade, P.A., and Reppert, S.M. (2003). Rhythmic histone acetylation underlies transcription in the mammalian circadian clock. Nature 421, 177-182.

Farré, E.M., Harmer, S.L., Harmon, F.G., Yanovsky, M.J., and Kay, S.A. (2005). Overlapping and distinct roles of PRR7 and PRR9 in the Arabidopsis circadian clock. Curr. Biol. 15, 47-54.

Flowers, T.J. (2004). Improving crop salt tolerance. J. Exp. Bot. 55, 307-319.

Flowers, T.J., and Colmer, T.D. (2008). Salinity tolerance in halophytes. New Phytol. 179, 945-963.

Flowers, T.J., Troke, P.F., and Yeo, A.R. (1977). The mechanism of salt tolerance in halophytes. Annu. Rev. Plant Physiol. 28, 89121.

Flowers, T., Galal, H., and Bromham, L. (2010). Evolution of halophytes: multiple origins of salt tolerance in land plants. Funct. Plant Biol. 37, 604-612.

Fowler, S., Lee, K., Onouchi, H., Samach, A., Richardson, K., Morris, B., Coupland, G., and Putterill, J. (1999). GIGANTEA: a circadian clock-controlled gene that regulates photoperiodic flowering in Arabidopsis and encodes a protein with several possible membrane-spanning domains. EMBO J. 18, 4679-4688.

Fowler, S.G., Cook, D., and Thomashow, M.F. (2005). Low temperature induction of Arabidopsis CBF1, 2, and 3 is gated by the circadian clock. Plant Physiol. 137, 961-968.

Fricke, W., Akhiyarova, G., Wei, W., Alexandersson, E., Miller, A., Kjellbom, P.O., Richardson, A., Wojciechowski, T., Schreiber, L., Veselov, D., et al. (2006). The short-term growth response to salt of the developing barley leaf. J. Exp. Bot. 57, 1079-1095.

Fujimori, T., Sato, E., Yamashino, T., and Mizuno, T. (2005). PRR5 (PSEUDO-RESPONSE REGULATOR 5) plays antagonistic roles to CCA1 (CIRCADIAN CLOCK-ASSOCIATED 1) in Arabidopsis thaliana. Biosci. Biotechnol. Biochem. 69, 426-430.

Gémes, K., Poór, P., Horváth, E., Kolbert, Z., Szopkó, D., Szepesi, Á., and Tari, I. (2011). Cross-talk between salicylic acid and $\mathrm{NaCl}-$ generated reactive oxygen species and nitric oxide in tomato during acclimation to high salinity. Physiol. Plant 142, 179-192.

Gepstein, S., Sabehi, G., Carp, M.-J., Hajouj, T., Nesher, M.F.O., Yariv, I., Dor, C., and Bassani, M. (2003). Large-scale identification of leaf senescence-associated genes. Plant J. 36, 629-642. 
Ghassemi, F., Jakeman, A.J., and Nix, H.A. (1995). "Salinisation of land and water resources: Human causes, extent, management, and case studies," (Wallingford, England: CAB international).

Gill, S.S., and Tuteja, N. (2010). Reactive oxygen species and antioxidant machinery in abiotic stress tolerance in crop plants. Plant Physiol. Biochem. 48, 909-930.

Graf, A., Schlereth, A., Stitt, M., and Smith, A.M. (2010). Circadian control of carbohydrate availability for growth in Arabidopsis plants at night. Proc. Natl. Acad. Sci. USA 107, 9458-9463

Hanikenne, M., Kroymann, J., Trampczynska, A., Bernal, M., Motte, P., Clemens, S., and Krämer, U. (2013). Hard selective sweep and ectopic gene conversion in a gene cluster affording environmental adaptation. PLoS Genet. 9, e1003707.

Hao, L., Zhao, Y., Jin, D., Zhang, L., Bi, X., Chen, H., Xu, Q., Ma, C. and Li, G. (2012). Salicylic acid-altering Arabidopsis mutants response to salt stress. Plant Soil. 354, 81-95.

Harmer, S.L. (2009). The circadian system in higher plants. Annu. Rev. Plant Biol. 60, 357-377.

Harmer, S.L., Hogenesch, J.B., Straume, M., Chang, H.-S., Han, B., Zhu, T., Wang, X., Kreps, J.A., and Kay, S.A. (2000). Orchestrated transcription of key pathways in Arabidopsis by the circadian clock. Science 290, 2110-2113.

Hedrich, R., and Neher, E. (1987). Cytoplasmic calcium regulates voltage-dependent ion channels in plant vacuoles. Nature 329, 833-836.

Hollister, J.D., Arnold, B.J., Svedin, E., Xue, K.S., Dilkes, B.P., and Bomblies, K. (2012). Genetic adaptation associated with genome-doubling in autotetraploid Arabidopsis arenosa. PLOS Genet. 8, e1003093.

Hong, S., Kim, S.A., Guerinot, M.L., and McClung, C.R. (2013). Reciprocal interaction of the circadian clock with the iron homeostasis network in Arabidopsis. Plant Physiol. 161, 893-903.

Horváth, E., Szalai, G., and Janda, T. (2007). Induction of abiotic stress tolerance by salicylic acid signaling. J. Plant Growth Regul. 26, 290-300.

Hotta, C.T., Gardner, M.J., Baek, S.J., Suhita, D., and Webb, A.A.R. (2007). Modulation of environmental responses of plants by circadian clocks. Plant Cell Env. 30, 333-349.

Howell, S.H. (2013). Endoplasmic Reticulum Stress Responses in Plants. Annu. Rev. Plant Biol. 64, 477-499.

Huq, E., Tepperman, J.M., and Quail, P.H. (2000). GIGANTEA is a nuclear protein involved in phytochrome signaling in Arabidopsis. Proc. Natl. Acad. Sci. USA 97, 9789-9794.

Jain, M., and Khurana, J.P. (2009). Transcript profiling reveals diverse roles of auxin-responsive genes during reproductive development and abiotic stress in rice. FEBS J. 276, 3148-3162.

Jayakannan, M., Bose, J., Babourina, O., Rengel, Z., and Shabala, S. (2013). Salicylic acid improves salinity tolerance in Arabidopsis by restoring membrane potential and preventing salt-induced $\mathrm{K}^{+}$ loss via a GORK channel. J. Exp. Bot. 64, 2255-2268.

Ji, H., Pardo, J.M., Batelli, G., Van Oosten, M.J., Bressan, R.A., and Li, X. (2013). The Salt Overly Sensitive (SOS) pathway: established and emerging roles. Mol. Plant. 6, 275-286.

Jiang, X., Leidi, E.O., and Pardo, J.M. (2010). How do vacuolar $\mathrm{NHX}$ exchangers function in plant salt tolerance? Plant Signal Behav. 5, 792-795.

Jibran, R., Hunter, D., and Dijkwel, P. (2013). Hormonal regulation of leaf senescence through integration of developmental and stress signals. Plant Mol. Biol. 82, 1-15.

Jung, C., and Müller, A.E. (2009). Flowering time control and applications in plant breeding. Trends Plant Sci. 14, 563-573.

Jung, J.-H., Seo, Y.-H., Seo, P.J., Reyes, J.L., Yun, J., Chua, N.-H., and Park, C.-M. (2007). The GIGANTEA-regulated MicroRNA172 mediates photoperiodic flowering independent of CONSTANS in Arabidopsis. Plant Cell 19, 2736-2748.

Kar, R.K. (2011). Plant responses to water stress: Role of reactive oxygen species. Plant Signal. Behav. 6, 1741-1745.

Katiyar-Agarwal, S., Zhu, J., Kim, K., Agarwal, M., Fu, X., Huang, A., and Zhu, J.-K. (2006). The plasma membrane $\mathrm{Na}^{+} / \mathrm{H}^{+}$antiporter SOS1 interacts with RCD1 and functions in oxidative stress tolerance in Arabidopsis. Proc. Natl. Acad. Sci. USA 103, 1881618821.

Kawasaki, S., Borchert, C., Deyholos, M., Wang, H., Brazille, S., Kawai, K., Galbraith, D., and Bohnert, H.J. (2001). Gene expression profiles during the initial phase of salt stress in rice. Plant Cell $13,889-905$.
Kellermeier, F., Chardon, F., and Amtmann, A. (2013). Natural variation of Arabidopsis root architecture reveals complementing adaptive strategies to potassium starvation. Plant Physiol. 161, 1421-1432.

Kende, H., and Zeevaart, J.A. (1997). The five "classical" plant hormones. Plant Cell 9, 1197-1210.

Ketchum, K., and Poole, R. (1991). Cytosolic calcium regulates a potassium current in corn (Zea mays) protoplasts. J. Membr. Biol.119, 277-288.

Kidokoro, S., Maruyama, K., Nakashima, K., Imura, Y., Narusaka, Y., Shinwari, Z. K., Osakabe, Y., Fujita, Y., Mizoi, J., Shinozaki, K., et al. (2009). The phytochrome-interacting factor PIF7 negatively regulates DREB1 expression under circadian control in $\mathrm{Ar}$ abidopsis. Plant Physiol. 151, 2046-2057.

Kim, B.-G., Waadt, R., Cheong, Y.H., Pandey, G.K., DominguezSolis, J.R., Schültke, S., Lee, S.C., Kudla, J., and Luan, S. (2007a). The calcium sensor CBL10 mediates salt tolerance by regulating ion homeostasis in Arabidopsis. Plant J. 52, 473-484.

Kim, D.-W., Shibato, J., Agrawal, G.K., Fujihara, S., Iwahashi, H., Kim, D.H., Shim, I.-S., and Rakwal, R. (2007b). Gene transcription in the leaves of rice undergoing salt-induced morphological changes (Oryza sativa L.). Mol. Cells 24, 45-59.

Kim, W.-Y., Fujiwara, S., Suh, S.-S., Kim, J., Kim, Y., Han, L., David K., Putterill, J., Nam, H.G., and Somers, D.E. (2007c). ZEITLUPE is a circadian photoreceptor stabilized by GIGANTEA in blue light. Nature 449, 356-360.

Kim, W.-Y., Salomé, P.A., Fujiwara, S., Somers, D.E., and McClung, C.R. (2010). Chapter 19 - Characterization of pseudo-response regulators in plants. In methods enzymol. Simon, Melvin I., Crane, Brian R., and Crane, Alexandrine eds., (Academic Press), pp. 357-378.

Kim, Y., Yeom, M., Kim, H., Lim, J., Koo, H. J., Hwang, D. Somers, D., and Nam, H.G. (2012). GIGANTEA and EARLY FLOWERING 4 in Arabidopsis exhibit differential phase-specific genetic influences over a diurnal cycle. Mol. Plant 5, 678-687.

Kim, W.-Y., Ali, Z., Park, H.J., Park, S.J., Cha, J.-Y., PerezHormaeche, J., Quintero, F.J., Shin, G., Kim, M.R., Qiang, Z., et al. (2013). Release of SOS2 kinase from sequestration with GIGANTEA determines salt tolerance in Arabidopsis. Nat. Commun. 4, 1352.

Kinnunen, P.K.J. (2000). Lipid bilayers as osmotic response elements. Cell. Physiol. Biochem. 10, 243-250.

König, S., Mosblech, A., and Heilmann, I. (2007). Stress-inducible and constitutive phosphoinositide pools have distinctive fatty acid patterns in Arabidopsis thaliana. FASEB J. 21, 1958-1967.

Kopittke, P. (2012). Interactions between $\mathrm{Ca}, \mathrm{Mg}, \mathrm{Na}$ and K: alleviation of toxicity in saline solutions. Plant Soil. 352, 353-362.

Krasensky, J., and Jonak, C. (2012). Drought, salt, and temperature stress-induced metabolic rearrangements and regulatory networks. J. Exp. Bot. 63, 1593-1608.

Krebs, M., Beyhl, D., Görlich, E., Al-Rasheid, K.A.S., Marten, I. Stierhof, Y.-D., Hedrich, R., and Schumacher, K. (2010). Arabidopsis V-ATPase activity at the tonoplast is required for efficient nutrient storage but not for sodium accumulation. Proc. Natl. Acad. Sci. USA 107, 3251-3256.

Kreps, J.A., Wu, Y., Chang, H.-S., Zhu, T., Wang, X., and Harper, J.F. (2002). Transcriptome Changes for Arabidopsis in response to salt, osmotic, and cold stress. Plant Physiol. 130, 2129-2141.

Krishnamurthy, A., and Rathinasabapathi, B. (2013). Auxin and its transport play a role in plant tolerance to arsenite-induced oxidative stress in Arabidopsis thaliana. Plant Cell Env. 36, 1838-1849.

Kronzucker, H.J., and Britto, D.T. (2011). Sodium transport in plants: a critical review. New Phytol. 189, 54-81.

Kurepa, J., Smalle, J., Va, M., Montagu, N., and Inzé, D. (1998). Oxidative stress tolerance and longevity in Arabidopsis: the lateflowering mutant gigantea is tolerant to paraquat. Plant J. 14, 759-764.

Lee, S.C., Lan, W.-Z., Kim, B.-G., Li, L., Cheong, Y.H., Pandey, G.K., Lu, G., Buchanan, B.B., and Luan, S. (2007). A protein phosphorylation/dephosphorylation network regulates a plant potassium channel. Proc. Natl. Acad. Sci. USA 104, 15959-15964.

Legnaioli, T., Cuevas, J., and Mas, P. (2009). TOC1 functions as a molecular switch connecting the circadian clock with plant responses to drought. EMBO J. 28, 3745-3757.

Li, K., Wang, Y., Han, C., Zhang, W., Jia, H., and Li, X. (2007). GA signaling and $\mathrm{CO} / \mathrm{FT}$ regulatory module mediate salt-induced late 
flowering in Arabidopsis thaliana. Plant Growth Regul. 53, 195206.

Lim, P.O., Kim, H.J., and Nam, G.H. (2007). Leaf senescence. Annu. Rev. Plant Biol. 58, 115-136.

Liu, X., Zhai, S., Zhao, Y., Sun, B., Liu, C., Yang, A., and Zhang, J. (2013a). Overexpression of the phosphatidylinositol synthase gene (ZmPIS) conferring drought stress tolerance by altering membrane lipid composition and increasing $A B A$ synthesis in maize. Plant Cell Environ. 36, 1037-1055

Liu, D., Ford, K.L., Roessner, U., Natera, S., Cassin, A.M., Patterson, J.H., and Bacic, A. (2013b). Rice suspension cultured cells are evaluated as a model system to study salt responsive networks in plants using a combined proteomic and metabolomic profiling approach. Proteomics 13, 2046-2062

Lutts, S., Kinet, J.M., and Bouharmont, J. (1995). Changes in plant response to $\mathrm{NaCl}$ during development of rice (Oryza sativa L.) varieties differing in salinity resistance. J. Exp. Bot. 46, 18431852.

Ma, T., Wang, J., Zhou, G., Yue, Z., Hu, Q., Chen, Y., Liu, B., Qiu, Q., Wang, Z., Zhang, J., et al. (2013). Genomic insights into salt adaptation in a desert poplar. Nat. Commun. 4, 2797

Maas, E.V., and Hoffman, G.J. (1977). Crop salt tolerance-current assessment. J. Irrig. Drain. Div. 103, 115-134.

Martínez-Atienza, J., Jiang, X., Garciadeblas, B., Mendoza, I., Zhu, J.-K., Pardo, J.M., and Quintero, F.J. (2007). Conservation of the salt overly sensitive pathway in rice. Plant Physiol. 143, 10011012.

del Martínez-Ballesta, M.C., Silva, C., López-Berenguer, C., Cabañero, F.J., and Carvajal, M. (2006). Plant aquaporins: new perspectives on water and nutrient uptake in saline environment. Plant Biol. 8, 535-546.

Mas, P., Kim, W.-Y., Somers, D.E., and Kay, S.A. (2003). Targeted degradation of TOC1 by ZTL modulates circadian function in $A r-$ abidopsis thaliana. Nature. 426, 567-570.

Maxwell, B.B., Andersson, C.R., Poole, D.S., Kay, S.A., and Chory, J. (2003). HY5, Circadian Clock-Associated 1, and a cis-Element, DET1 Dark Response Element, mediate DET1 regulation of Chlorophyll a/b-Binding Protein 2 Expression. Plant Physiol. 133, 1565-1577.

McClung, C.R. (2011). "Chapter 4 - The Genetics of Plant Clocks," in Adv. Genet., ed. Stuart Brody (Academic Press), pp. 105-139.

McClung, C.R., and Davis, S.J. (2010). Ambient thermometers in plants: from physiological outputs towards mechanisms of thermal sensing. Curr. Biol. 20, R1086-R1092.

Michael, T.P., Breton, G., Hazen, S.P., Priest, H., Mockler, T.C., Kay, S.A., and Chory, J. (2008). A morning-specific phytohormone gene expression program underlying rhythmic plant growth PLoS Biol. 6, e225.

Miller, G., Suzuki, N., Ciftci-Yilmaz, S., and Mittler, R. (2010). Reactive oxygen species homeostasis and signalling during drought and salinity stresses. Plant Cell Env. 33, 453-467.

Mittova, V., Tal, M., Volokita, M., and Guy, M. (2002). Salt stress induces up-regulation of an efficient chloroplast antioxidant system in the salt-tolerant wild tomato species Lycopersicon pennellii but not in the cultivated species. Physiol. Plant 115, 393-400.

Mizoguchi, T., Wright, L., Fujiwara, S., Cremer, F., Lee, K., Onouchi, H., Mouradov, A., Fowler, S., Kamada, H., Putterill, J., et al. (2005). Distinct roles of GIGANTEA in promoting flowering and regulating circadian rhythms in Arabidopsis. Plant Cell 17, 22552270.

Munné-Bosch, S., and Alegre, L. (2004). Die and let live: leaf senescence contributes to plant survival under drought stress. Funct. Plant Biol. 31, 203-216.

Munnik T., and Vermeer, J.E.M. (2010). Osmotic stress-induced phosphoinositide and inositol phosphate signalling in plants. Plant Cell Environ. 33, 655-669.

Munns, R. (2002). Comparative physiology of salt and water stress. Plant Cell Env. 25, 239-250.

Munns, R. (2005). Genes and salt tolerance: bringing them together. New Phytol. 167, 645-663.

Munns, R., and Tester, M. (2008). Mechanisms of salinity tolerance. Annu. Rev. Plant Biol. 59, 651-681.

Nagamiya, K., Motohashi, T., Nakao, K., Prodhan, S., Hattori, E., Hirose, S., Ozawa, K., Ohkawa, Y., Takabe, T., Takabe, T., et al. (2007). Enhancement of salt tolerance in transgenic rice expressing an Escherichia coli catalase gene, katE. Plant Biotechnol.
Rep. 1, 49-55.

Nakagami, H., Pitzschke, A., and Hirt, H. (2005). Emerging MAP kinase pathways in plant stress signalling. Trends Plant Sci. 10, 339-346.

Nakamichi, N., Kita, M., Ito, S., Sato, E., Yamashino, T., and Mizuno, T. (2005a). The Arabidopsis Pseudo-response Regulators, PRR5 and PRR7, coordinately play essential roles for circadian clock function. Plant Cell Physiol. 46, 609-619.

Nakamichi, N., Kita, M., Ito, S., Yamashino, T., and Mizuno, T. (2005b). PSEUDO-RESPONSE REGULATORS, PRR9, PRR7 and PRR5, together play essential roles close to the circadian clock of Arabidopsis thaliana. Plant Cell Physiol. 46, 686-698.

Nakamichi, N., Kusano, M., Fukushima, A., Kita, M., Ito, S., Yamashino, T., Saito, K., Sakakibara, H., and Mizuno, T. (2009). Transcript profiling of an Arabidopsis PSEUDO RESPONSE REGULATOR arrhythmic triple mutant reveals a role for the circadian clock in cold stress response. Plant Cell Physiol. 50, 447462.

Nawaz, K., Hussain, K., Majeed, A., Khan, F., Afghan, S., and Ali, K. (2010). Fatality of salt stress to plants: Morphological, physiological and biochemical aspects. Afr. J .Biotechnol. 9, 5475 - 5480.

Nuccio, M.L., Rhodest, D., McNeil, S.D., and Hanson, A.D. (1999). Metabolic engineering of plants for osmotic stress resistance. Curr. Opin. Plant Biol. 2, 128-134.

Oh, D.-H., Lee, S.Y., Bressan, R.A., Yun, D.-J., and Bohnert, H.J. (2010). Intracellular consequences of SOS1 deficiency during salt stress. J. Exp. Bot. 61, 1205-1213.

Oh, D.-H., Hong, H., Lee, S.Y., Yun, D.-J., Bohnert, H.J., and Dassanayake, M. (2014). Genome Structures and Transcriptomes Signify Niche Adaptation for the Multiple-Ion-Tolerant Extremophyte Schrenkiella parvula. Plant Physiol. 164, 2123-2138.

Olías, R., Eljakaoui, Z., Li, J., De Morales, P. A., Carmen, M.-M.M., Pardo, J.M., and Belver, A. (2009). The plasma membrane $\mathrm{Na}^{+} / \mathrm{H}^{+}$antiporter SOS1 is essential for salt tolerance in tomato and affects the partitioning of $\mathrm{Na}^{+}$between plant organs. Plant Cell Env. 32, 904-916.

Oliverio, K.A., Crepy, M., Martin-Tryon, E.L., Milich, R., Harmer S.L., Putterill, J., Yanovsky, M.J., and Casal, J.J. (2007). GIGANTEA regulates phytochrome a-mediated photomorphogenesis independently of its role in the circadian clock. Plant Physiol. 144, 495-502.

Olszewski, N., Sun, T., and Gubler, F. (2002). Gibberellin signaling: biosynthesis, catabolism, and response pathways. Plant Cell 14 S61-S80.

Olszewski, N.E., West, C.M., Sassi, S.O., and Hartweck, L.M. (2010). O-GIcNAc protein modification in plants: evolution and function. Biochim. Biophys. Acta. 1800, 49-56.

Opdenakker, K., Remansemail, T., Vangronsveld, J., and Cuypers, A. (2012). Mitogen-activated protein (MAP) kinases in plant metal stress: regulation and responses in comparison to other biotic and abiotic stresses. Int. J. Mol. Sci. 13, 7828-7853.

Paltiel, J., Amin, R., Gover, A., Ori, N., and Samach, A. (2006). Novel roles for GIGANTEA revealed under environmental conditions that modify its expression in Arabidopsis and Medicago truncatula. Planta 224, 1255-1268.

Pardo, J.M. (2010). Biotechnology of water and salinity stress tolerance. Curr. Opin. Biotech. 21, 185-196.

Park, D.H., Somers, D.E., Kim, Y.S., Choy, Y.H., Lim, H.K., Soh, M.S., Kim, H.J., Kay, S.A., and Nam, H.G. (1999). Control of circadian rhythms and photoperiodic flowering by the Arabidopsis GIGANTEA gene. Science 285, 1579-1582.

Park, H.J., Kim, W.-Y., and Yun, D.-J. (2013). A role for GIGANTEA: Keeping the balance between flowering and salinity stress tolerance. Plant Signal. Behav. 8, e24820.

Perales, M., and Más, P. (2007). A functional link between rhythmic changes in chromatin structure and the Arabidopsis biological clock. Plant Cell 19, 2111-2123.

Pyo, Y.J., Gierth, M., Schroeder, J.I., and Cho, M.H. (2010). Highaffinity $\mathrm{K}^{+}$transport in Arabidopsis: AtHAK5 and AKT1 are vital for seedling establishment and postgermination growth under low-potassium conditions. Plant Physiol. 153, 863-875.

Qi, Z., and Spalding, E.P. (2004). Protection of plasma membrane $\mathrm{K}^{+}$transport by the salt overly sensitive1 $\mathrm{Na}^{+} / \mathrm{H}^{+}$antiporter during salinity stress. Plant Physiol. 136, 2548-2555.

Qin, F., Kodaira, K.-S., Maruyama, K., Mizoi, J., Tran, L.-S. P., Fujita, Y., Morimoto, K., Shinozaki, K., and Yamaguchi-Shinozaki, 
K. (2011). SPINDLY, a negative regulator of gibberellic acid signaling, is involved in the plant abiotic stress response. Plant Physiol. 157, 1900-1913.

Quintero, F. ., Ohta, M., Shi, H., Zhu, J.-K., and Pardo, J.M. (2002). Reconstitution in yeast of the Arabidopsis SOS signaling pathway for $\mathrm{Na}^{+}$homeostasis. Proc. Natl. Acad. Sci. USA 99, 90619066.

Rengel, Z. (1992). The role of calcium in salt toxicity. Plant Cell Env. $15,625-632$

Riboni, M., Galbiati, M., Tonelli, C., and Conti, L. (2013). GIGANTEA enables drought escape response via abscisic aciddependent activation of the florigens and SUPPRESSOR OF OVEREXPRESSION OF CONSTANS1. Plant Physiol. 162, 1706-1719.

Rivas-San Vicente, M., and Plasencia, J. (2011). Salicylic acid beyond defence: its role in plant growth and development. J. Exp. Bot. 62, 3321-3338

Rodrigo-Moreno, A., Poschenrieder, C., and Shabala, S. (2013). Transition metals: A double edge sward in ROS generation and signaling. Plant Signal. Behav. 8, e23425.

Rontein, D., Basset, G., and Hanson, A.D. (2002). Metabolic engineering of osmoprotectant accumulation in plants. Metab. Eng. 4, 49-56.

Rosa, M., Prado, C., Podazza, G., Interdonato, R., González, J.A., Hilal, M., and Prado, F.E. (2009). Soluble sugars: Metabolism, sensing and abiotic stress: a complex network in the life of plants. Plant Signal. Behav. 4, 388-393.

Rus, A., Yokoi, S., Sharkhuu, A., Reddy, M., Lee, B., Matsumoto, T.K., Koiwa, H., Zhu, J.-K., Bressan, R.A., and Hasegawa, P. M. (2001). AtHKT1 is a salt tolerance determinant that controls $\mathrm{Na}^{+}$ entry into plant roots. Proc. Natl. Acad. Sci. USA 98, 1415014155.

Rus, A., Lee, B., Muñoz-Mayor, A., Sharkhuu, A., Miura, K., Zhu, J.K., Bressan, R.A., and Hasegawa, P.M. (2004). AtHKT1 facilitates $\mathrm{Na}^{+}$homeostasis and $\mathrm{K}^{+}$nutrition in planta. Plant Physiol. $136,2500-2511$.

Sahi, C., Singh, A., Kumar, K., Blumwald, E., and Grover, A. (2006). Salt stress response in rice: genetics, molecular biology, and comparative genomics. Funct. Integr. Genomics 6, 263-284.

Sairam, R.K., and Tyagi, A. (2004). Physiology and molecular biology of salinity stress tolerance in plants. Curr. Sci. 86, 407-421.

Sakamoto, A., and Murata, N. (2002). The role of glycine betaine in the protection of plants from stress: clues from transgenic plants. Plant Cell Env. 25, 163-171.

Salomé, P.A., and McClung, C.R. (2005). PSEUDO-RESPONSE REGULATOR 7 and 9 are partially redundant genes essential for the temperature responsiveness of the Arabidopsis circadian clock. Plant Cell 17, 791-803.

Salter, M.G., Franklin, K.A., and Whitelam, G.C. (2003). Gating of the rapid shade-avoidance response by the circadian clock in plants. Nature. 426, 680-683.

Sanders, D., Pelloux, J., Brownlee, C., and Harper, J.F. (2002). Calcium at the crossroads of signaling. Plant Cell 14, S401-S417.

Sanchez, A., Shin, J., and Davis, S.J. (2011). Abiotic stress and the plant circadian clock. Plant Signal. Behav. 6, 223-231.

Sawa, M., and Kay, S.A. (2011). GIGANTEA directly activates Flowering Locus T in Arabidopsis thaliana. Proc. Natl. Acad. Sci. USA 108, 11698-11703.

Sawa, M., Nusinow, D.A., Kay, S.A., and Imaizumi, T. (2007). FKF1 and GIGANTEA complex formation is required for day-length measurement in Arabidopsis. Science 318, 261-265.

Schaffer, R., Ramsay, N., Samach, A., Corden, S., Putterill, J., Carré, I.A., and Coupland, G. (1998). The late elongated hypocotyl mutation of Arabidopsis disrupts circadian rhythms and the photoperiodic control of flowering. Cell 93, 1219-1229.

Sehgal, D., Rajaram, V., Armstead, I., Vadez, V., Yadav, Y., Hash, C., and Yadav, R. (2012). Integration of gene-based markers in a pearl millet genetic map for identification of candidate genes underlying drought tolerance quantitative trait loci. BMC Plant Biol. $12,9$.

Seo, P., Park, J.-M., Kang, S., Kim, S.-G., and Park, C.-M. (2011). An Arabidopsis senescence-associated protein SAG29 regulates cell viability under high salinity. Planta 233, 189-200.

Seung, D., Risopatron, J., Jones, B., and Marc, J. (2012). Circadian clock-dependent gating in ABA signalling networks. Protoplasma $249,445-457$.
Shabala, S., and Cuin, T.A. (2007). Potassium transport and plant salt tolerance. Physiol. Plant 133, 651-669.

Shao, H.-B., Chu, L.-Y., Lu, Z.-H., and Kang, C.-M. (2008). Primary antioxidant free radical scavenging and redox signaling pathways in higher plant cells. Int. J. Biol. Sci. 4, 8-14.

Shatil-Cohen, A., Attia, Z., and Moshelion, M. (2011). Bundlesheath cell regulation of xylem-mesophyll water transport via aquaporins under drought stress: a target of xylem-borne ABA? Plant J. 67, 72-80.

Shavrukov, Y. (2013). Salt stress or salt shock: which genes are we studying? J. Exp. Bot. 64, 119-127.

Shen, B., Jensen, R.G., and Bohnert, H.J. (1997). Mannitol protects against oxidation by hydroxyl radicals. Plant Physiol. 115, 527532.

Shi, H., Ishitani, M., Kim, C., and Zhu, J.-K. (2000). The Arabidopsis thaliana salt tolerance gene SOS1 encodes a putative $\mathrm{Na}^{+} / \mathrm{H}^{+}$antiporter. Proc. Natl. Acad. Sci. USA 97, 6896-6901.

Shi, H., Quintero, F.J., Pardo, J.M., and Zhu, J.-K. (2002). The putative plasma membrane $\mathrm{Na}^{+} / \mathrm{H}^{+}$antiporter SOS1 controls long-distance $\mathrm{Na}^{+}$transport in plants. Plant Cell 14, 465-477.

Shi, H., Lee, B., Wu, S.-J., and Zhu, J.-K. (2003). Overexpression of a plasma membrane $\mathrm{Na}^{+} / \mathrm{H}^{+}$antiporter gene improves salt tolerance in Arabidopsis thaliana. Nat. Biotech. 21, 81-85.

Sothern, R.B., Tseng, T.-S., Orcutt, S.L., Olszewski, N.E., and Koukkari, W.L. (2002). GIGANTEA and SPINDLY genes linked to the clock pathway that controls circadian characteristics of transpiration in Arabidopsis. Chronobiol. Int. 19, 1005-1022.

Sunkar, R., Kapoor, A., and Zhu, J.-K. (2006). Posttranscriptional induction of two Cu/Zn superoxide dismutase genes in Arabidopsis is mediated by downregulation of miR398 and important for oxidative stress tolerance. Plant Cell 18, 2051-2065.

Szczerba, M.W., Britto, D.T., and Kronzucker, H.J. (2009). $\mathrm{K}^{+}$ transport in plants: Physiology and molecular biology. J. Plant Physiol. 166, 447-466.

Tang, R.-J., Liu, H., Bao, Y., Lv, Q.-D., Yang, L., and Zhang, H.-X (2010). The woody plant poplar has a functionally conserved salt overly sensitive pathway in response to salinity stress. Plant Mol. Biol. 74, 367-380.

Thain, S.C., Vandenbussche, F., Laarhoven, L.J.J., Dowson-Day, M.J., Wang, Z.-Y., Tobin, E.M., Harren, F.J. M., Millar, A.J., and Van Der Straeten, D. (2004). Circadian rhythms of ethylene emission in Arabidopsis. Plant Physiol. 136, 3751-3761.

Thines, B., and Harmon, F.G. (2011). Four easy pieces: mechanisms underlying circadian regulation of growth and development. Curr. Opin. Plant Biol. 14, 31-37.

Tripathy, B.C., and Oelmüller, R. (2012). Reactive oxygen species generation and signaling in plants. Plant Signal. Behav. 7, 16211633.

Tseng, T.-S., Salomé, P.A., McClung, C.R., and Olszewski, N.E. (2004). SPINDLY and GIGANTEA interact and act in Arabidopsis thaliana pathways involved in light responses, flowering, and rhythms in cotyledon movements. Plant Cell 16, 1550-1563.

Tyerman, S.D., Bohnert, H.J., Maurel, C., Steudle, E., and Smith, J.A.C. (1999). Plant aquaporins: their molecular biology, biophysics and significance for plant water relations. J. Exp. Bot. 50, 1055-1071.

Umezawa, T., Fujita, M., Fujita, Y., Yamaguchi-Shinozaki, K., and Shinozaki, K. (2006). Engineering drought tolerance in plants: discovering and tailoring genes to unlock the future. Curr. Opin. Plant Biotech. 17, 113-122.

Ushakova, S.A., Kovaleva, N.P., Gribovskaya, I.V., Dolgushev, V.A. and Tikhomirova, N. A. (2005). Effect of $\mathrm{NaCl}$ concentration on productivity and mineral composition of Salicornia europaea as a potential crop for utilization $\mathrm{NaCl}$ in LSS. Adv. Space Res. 36, 1349-1353.

Vaidyanathan, H., Sivakumar, P., Chakrabarty, R., and Thomas, G. (2003). Scavenging of reactive oxygen species in $\mathrm{NaCl}$-stressed rice (Oryza sativa L.) - differential response in salt-tolerant and sensitive varieties. Plant Sci. 165, 1411-1418.

Verslues, P. E., Batelli, G., Grillo, S., Agius, F., Kim, Y.-S., Zhu, J., Agarwal, M., Katiyar-Agarwal, S., and Zhu, J.-K. (2007). Interaction of SOS2 with nucleoside diphosphate kinase 2 and catalases reveals a point of connection between salt stress and $\mathrm{H}_{2} \mathrm{O}_{2}$ signaling in Arabidopsis thaliana. Mol. Cell Biol. 27, 77717780 .

Wahid, A., Gelani, S., Ashraf, M., and Foolad, M.R. (2007). Heat 
tolerance in plants: sn overview. Env. Exp. Bot. 61, 199-223.

Wang, X.-F., and Zhang, A.-P. (2008). Abscisic acid receptors: Multiple signal-perception sites. Ann. Bot. 101, 311-317.

Wang, Z.Y., Kenigsbuch, D., Sun, L., Harel, E., Ong, M.S., and Tobin, E. M. (1997). A Myb-related transcription factor is involved in the phytochrome regulation of an Arabidopsis Lhcb gene. Plant Cell 9, 491-507.

Wang, S., Bai, Y., Shen, C., Wu, Y., Zhang, S., Jiang, D., Guilfoyle, T., Chen, M., and Qi, Y. (2010). Auxin-related gene families in abiotic stress response in Sorghum bicolor. Funct. Integr. Genomics. 10, 533-546.

Wang, W., Barnaby, J.Y., Tada, Y., Li, H., Tor, M., Caldelari, D., Lee, D., Fu, X.-D., and Dong, X. (2011). Timing of plant immune responses by a central circadian regulator. Nature. 470, 110-114.

Weigel, D. (2012). Natural variation in Arabidopsis: from molecular genetics to ecological genomics. Plant Physiol. 158, 2-22.

Wilkins, O., Bräutigam, K., and Campbell, M.M. (2010). Time of day shapes Arabidopsis drought transcriptomes. Plant J. 63, 715-727.

Wu, Y., Ding, N., Zhao, X., Zhao, M., Chang, Z., Liu, J., and Zhang, L. (2007). Molecular characterization of PeSOS1: the putative $\mathrm{Na}^{+} / \mathrm{H}^{+}$antiporter of Populus euphratica. Plant Mol. Biol. 65, 1-11.

Wu, H.-J., Zhang, Z., Wang, J.-Y., Oh, D.-H., Dassanayake, M., Liu, B., Huang, Q., Sun, H.-X., Xia, R., Wu, Y., et al. (2012). Insights into salt tolerance from the genome of Thellungiella salsuginea. Proc. Natl. Acad. Sci. USA 109, 12219-12224.

Xu, X., Hotta, C.T., Dodd, A.N., Love, J., Sharrock, R., Lee, Y.W., Xie, Q., Johnson, C.H., and Webb, A.A.R. (2007). Distinct light and clock modulation of cytosolic free $\mathrm{ca}^{2+}$ oscillations and rhythmic chlorophyll a/b binding protein2 promoter activity in Arabidopsis. Plant Cell 19, 3474-3490.

Xu, H., Jiang, X., Zhan, K., Cheng, X., Chen, X., Pardo, J.M., and Cui, D. (2008). Functional characterization of a wheat plasma membrane $\mathrm{Na}^{+} / \mathrm{H}^{+}$antiporter in yeast. Arch. Biochem. Biophys. 473, 8-15.

Xu, X., Graeff, R., Xie, Q., Gamble, K.L., Mori, T., and Johnson, C. $\mathrm{H}$. (2009). Comment on "The Arabidopsis circadian clock incorporates a cADPR-based feedback loop." Science. 326, 230-230.

Yang, Q., Chen, Z.-Z., Zhou, X.-F., Yin, H.-B., Li, X., Xin, X.-F. Hong, X.-H., Zhu, J.-K., and Gong, Z. (2009). Overexpression of sos (salt overly sensitive) genes increases salt tolerance in transgenic Arabidopsis. Mol. Plant 2, 22-31.

Yensen, N. (2006). Halophyte uses for the twenty-first century. In ecophysiology of high salinity tolerant plants tasks for vegetation science., M.A. Khan and D. Weber eds. (Springer Netherlands), pp. 367-396.

Yeo, A.R., and Flowers, T.J. (1980). Salt tolerance in the halophyte Suaeda maritima L. Dum.: Evaluation of the effect of salinity upon growth. J. Exp. Bot. 31, 1171-1183.

Yoshimura, K., Miyao, K., Gaber, A., Takeda, T., Kanaboshi, H., Miyasaka, H., and Shigeoka, S. (2004). Enhancement of stress tolerance in transgenic tobacco plants overexpressing Chlamydomonas glutathione peroxidase in chloroplasts or cytosol. Plant J. 37, 21-33.

Yuan, S., and Lin, H.-H. (2008). Role of salicylic acid in plant abiotic stress. Z. Naturforsch 63,313-320.

Zhai, S.-M., Gao, Q., Xue, H.-W., Sui, Z.-H., Yue, G.-D., Yang, A.-F., and Zhang, J.-R. (2012). Overexpression of the phosphatidylinositol synthase gene from Zea mays in tobacco plants alters the membrane lipids composition and improves drought stress tolerance. Planta 235, 69-84.

Zhang, H.-X., and Blumwald, E. (2001). Transgenic salt-tolerant tomato plants accumulate salt in foliage but not in fruit. Nat. Biotech. 19, 765-768.

Zhang, J., Jia, W., Yang, J., and Ismail, A.M. (2006). Role of ABA in integrating plant responses to drought and salt stresses. Field Crops Res. 97, 111-119.

Zhang, J., Lu, Y., Yuan, Y., Zhang, X., Geng, J., Chen, Y., Cloutier, S., McVetty, P.B.E., and Li, G. (2009). Map-based cloning and characterization of a gene controlling hairiness and seed coat color traits in Brassica rapa. Plant Mol. Biol. 69, 553 - 563.

Zhou, S., Hu, W., Deng, X., Ma, Z., Chen,, L., Huang, C., Wang, C. Wang, J., He, Y., Yang, G., et al. (2012). Overexpression of the wheat aquaporin gene, TaAQP7, enhances drought tolerance in transgenic tobacco. PLoS One 7, e52439.

Zhu, J.-K. (2001). Plant salt tolerance. Trends Plant Sci. 6, 66-71.

Zhu, J.-K. (2002). Salt and drought stress signal transduction in plants. Annu. Rev. Plant Biol. 53, 247-273.

Zhu, J.-K. (2003). Regulation of ion homeostasis under salt stress. Curr. Opin. Plant Biol. 6, 441-445.

Zhu, J. (2007). Plant salt stress. In encyclopedia of life sciences (John Wiley \& Sons).

Zhu, J.-K., Liu, J., and Xiong, L. (1998). Genetic analysis of salt tolerance in Arabidopsis: evidence for a critical role of potassium nutrition. Plant Cell 10, 1181-1191. 